\title{
Manufacturing Metrology for c-Si Photovoltaic Module Reliability and Durability \\ Part I: Feedstock, Crystallization and Wafering
}

Hubert Seigneur $^{1,2}$, Nahid Mohajeri ${ }^{1,2}$, R. Paul Brooker ${ }^{1,2}$, Kristopher O. Davis ${ }^{1,2,3}$, Eric J. Schneller ${ }^{1,2}$, Neelkanth G. Dhere ${ }^{2}$, Marianne P.Rodgers ${ }^{1,2}$, John Wohlgemuth ${ }^{4}$, Narendra S. Shiradkar ${ }^{2}$, Giuseppe Scardera ${ }^{5}$, Andrew C. Rudack ${ }^{1,6}$, Winston V. Schoenfeld ${ }^{1,2,3}$

1. c-Si Division, U.S. Photovoltaic Manufacturing Consortium, 12354 Research Parkway - Suite 210, Orlando, FL 32826, USA

2. Florida Solar Energy Center, University of Central Florida, 1679 Clearlake Road, Cocoa, FL 32922, USA

3. CREOL, The College of Optics and Photonics, 4000 Central Florida Boulevard, Orlando, FL 32826, USA

4. National Renewable Energy Laboratory, 1617 Cole Boulevard, Golden, Co 80401, USA

5. DuPont Silicon Valley Technology Center, 965 East Arques Avenue, Sunnyvale, CA 94085, USA

6. SEMATECH, 257 Fuller Road, Albany, NY 12203 USA

Corresponding Author: Hubert Seigneur, Hubert.seigneur@uspvmc.org

\begin{abstract}
This article is the first in a three-part series of manufacturing metrology for c-Si photovoltaic (PV) module reliability and durability. Here in Part 1 we focus on the three primary process steps for making silicon substrates for PV cells: (1) feedstock production; (2) ingot and brick production; and (3) wafer production. Each of these steps can affect the final reliability/durability of PV modules in the field with manufacturing metrology potentially playing a significant role. This article provides a comprehensive overview of historical and current processes in each of these three steps, followed by a discussion of associated reliability challenges and metrology strategies that can be employed for increased reliability and durability in resultant modules. Gaps in the current state of understanding in connective metrology data during processing to reliability/durability in the field are then identified along with suggested improvements that should be considered by the PV community.
\end{abstract}

\section{Keywords}

Polysilicon, Siemens, Fluidized bed reactor, Impurity, Czochralski, Ingot, Directional solidification, Crystalline silicon, Wafer, Kerfless, Light induced degradation, Crack, Shunt, Residual stress.

\section{Introduction}

Silicon, the most earth-abundant element in the periodic table after oxygen, accounts for $25.7 \%$ of the earth's crust and is mainly found as silicon oxides, in the form of silicate minerals. The production and purification of silicon dates back to the 1800s; however, current commercial methods were primarily developed in the 1900s. The process for making silicon substrates for PV cells can be divided into three different steps: (1) feedstock production, (2) ingot production, and (3) wafer production. Each of these 
steps can in some way affect the final reliability/durability of PV modules in the field. Here we review each of these steps successively.

The scope for silicon feedstock production typically encompasses all processes needed to transform sand into polycrystalline chunks of silicon. These are in essence refining processes that are mainly classified in terms of grade or purity, process phase (metallurgical route, gaseous route, etc), cost, and energy consumption. This article reviews the majority of feedstock production processes used to create metallurgical grade silicon (MG-Si), upgraded metallurgical grade silicon (UMG-Si), and electronic grade silicon (EG-Si) before focusing on the main competing commercial technologies i.e. Siemens, fluidized bed reactor, and UMG silicon [1]. The Siemens and the fluidized bed processes account for the great majority of polysilicon used in crystalline silicon (c-Si) solar cell production.

The scope for ingot production includes techniques for monocrystalline silicon (mono-Si) such as the Czochralski (CZ) or float-zone (FZ) method, for multicrystalline silicon (multi-Si) such as casting and directional solidification DS, and for quasi-monocrystalline silicon (i.e. mono-like). Ingot production is mainly classified in terms of the resulting crystallinity of the ingot, which can be explained in terms of the grain size. Polycrystalline silicon, typically not used in PV applications, consists of a grain size on the order of nanometers $(\mathrm{nm})$ to microns $(\mu \mathrm{m})$. Multi-Si consists of grain sizes on the order of $\mu \mathrm{m}$ to millimeters $(\mathrm{mm})$, while mono-Si occurs when the whole ingot is a single grain. Mono-like Si falls somewhere in between multi-Si and mono-Si. Typically, a Mono-like silicon ingot would consist of very large single grain occupying $60-80 \%$ of the total volume surrounded by multi-Si. These are not to be confused with nanocrystalline silicon (nc-Si) and microcrystalline silicon ( $\mu \mathrm{c}-\mathrm{Si}$ ), which are forms of porous silicon that cannot be generated during ingot production. In fact, these have a paracrystalline structure, which consists of a mixture of small grains of crystalline silicon and an amorphous phase. Mono-Si CZ accounts for $40 \%$ of all c-Si solar cells while $60 \%$ are made from multi-Si according to the 2014 edition of the International Technology Roadmap for Photovoltaics (ITRPV www.itrpv.net). Reviews of silicon crystal growth for photovoltaics are available in the literature [2-4].

The scope for wafer production includes techniques for wire sawing such as slurry-based wire sawing and diamond-based wire sawing as well as kerfless wafering techniques such as the implant-cleave method, the exfoliation method, ribbon growth processes, and epitaxial growth processes. Today, most, if not all wafers used for crystalline silicon solar cells are produced using a wire sawing method. Reviews of wire sawing are available in the literature $[5,6]$. According to the 2014 edition of the ITRPV, diamond wire sawing is expected to take over as the main wire sawing method in the near future.

This article is the first in a series dedicated to reviewing the impact of each processing step on PV module performance and reliability and identifying relevant metrology techniques that can be utilized to improve the quality and durability of the final product. The subsequent articles in this series have a focus in the areas of cell manufacturing (Part 2) and module manufacturing (Part 3). The focus of this article is the module manufacturing process (see Figure 1). The goals of this work are to:

1. Identify known failure modes and degradation mechanisms induced during manufacturing

2. Provide a review of the current state of metrology used during manufacturing for improved PV reliability and durability $[7,8]$ 
3. Perform a gap analysis and identify where improvements can be made [9]

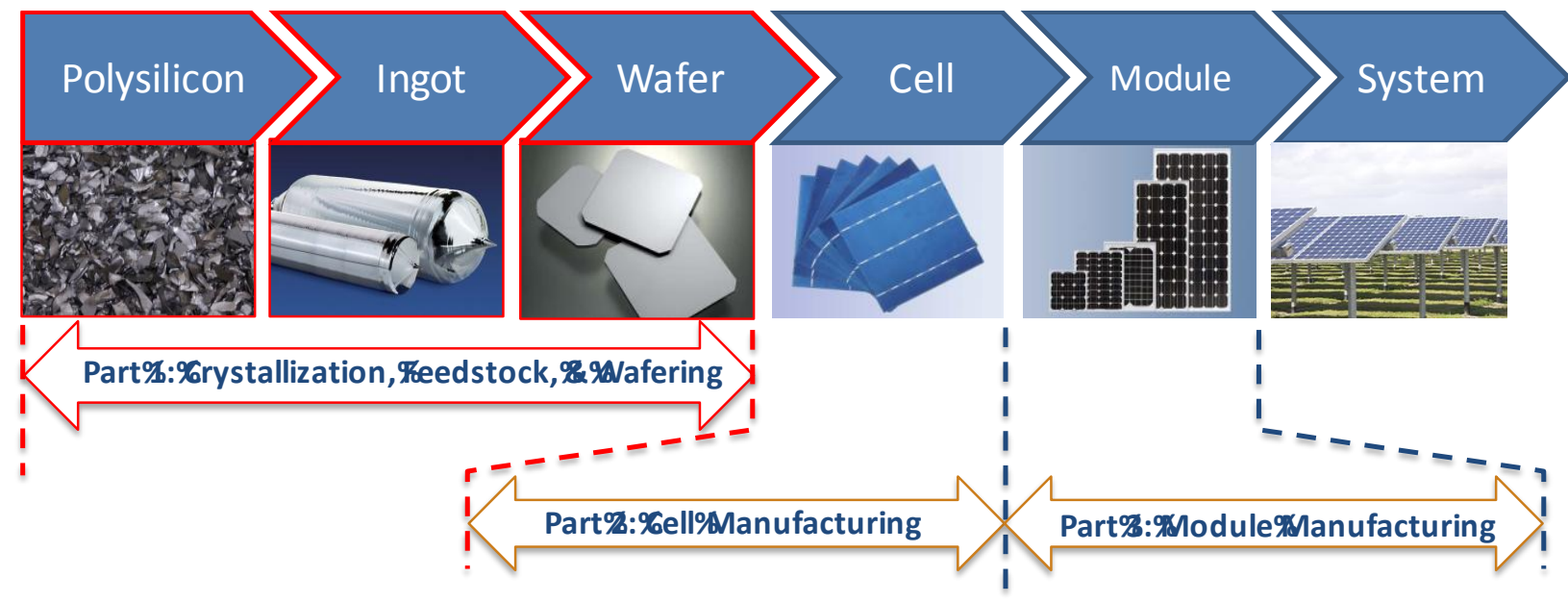

Figure 1. Depiction of c-Si PV manufacturing production areas across the supply chain highlighting feedstock, crystallization and wafering as the focus of this article.

\section{Feedstock Production}

The key for improving future c-Si module reliability and durability during feedstock production is being able to control the type and concentration of impurities present in the feedstock, which is process dependent, and doing so while maintaining or even reducing cost. Sensible metrology in process control and quality control can help in this regard. Ultimately, this is a convoluted challenge as crystal growth introduces new impurities as well as redistributes impurities existing within the polysilicon feedstock as a function of the growth technique, the furnace geometry, the heating scheme, and individual segregation coefficients of the various impurities. Introduction and redistribution of impurities occurs along the entire downstream manufacturing chain, from wafering processes, to cell fabrication, to module fabrication, and continues even after the modules are installed in the field (e.g. light induced degradation, etc). As a result, impurity control is very challenging. Nonetheless, this section on feedstock production aims to: (1) highlight the various processes (both conventional and unconventional) used to produce various grades of polysilicon and the impurity profile associated with each (where available); (2) increase the understanding of the redistribution that occurs in the impurity profiles between various grades of polysilicon and the resulting "usable" bulk material after crystal growth; and (3) recommend strategies for manufacturing metrology in the context of feedstock production. Understanding which impurities affect PV reliability and durability and being able to effectively measure critical impurity levels early in the process can be advantageous

In general, the grand challenges for feedstock production over the past few years have been to lower cost and energy consumption in kilowatt-hour per watt-peak ( $\mathrm{kWh} / \mathrm{Wp})$, improve energy density in kilowatt-hour per kilogram ( $\mathrm{kWh} / \mathrm{kg}$ ), improve gas/byproducts recycling and reuse, increase the purity to $7 \mathrm{~N}$ (99.99999\%) or higher, especially for solar grade polysilicon (SoG-Si) made from UMG processes, and unify and promote industry-wide adoption of materials standards and methodology for characterizing feedstock quality. In addition to increasing the purity, it is just as important, if not more important, to identify killer impurities versus impurities with only minor impacts. The impact of 
impurities on cell and module performance increases for advanced architectures [10] and, contrary to popular belief, even if $n$-type substrates are used [11]. For example, chromium has been found to be extremely detrimental to $n$-type substrates, whereas Fe tends to be the problem for $p$-type. It has been reported [12] that the cost of feedstock produced by different feedstock production processes changes the cost of the c-Si modules by $11 \%$ for standard technologies and up to $7 \%$ for advanced technologies, conditional on maintaining the cell efficiency. If the cell efficiency cannot be maintained, then the low cost advantage of UMG-Si is lost due to quality degradation of $1.7 \%$ for a standard module technology.

Table 1 describes impurities currently specified in the PV industry standards (i.e. SEMI PV 017 standards) for solar grade feedstock:

Table 1. Impurities currently specified in industry standards for Solar Grade feedstock

\begin{tabular}{ll}
\hline Impurity Type & Element \\
\hline Acceptor & $\mathrm{B}, \mathrm{Al}$ \\
Donor & $\mathrm{P}, \mathrm{As}, \mathrm{Sb}$ \\
Atmospheric & $\mathrm{O}, \mathrm{N}, \mathrm{C}$ \\
Transition metals & $\mathrm{Fe}, \mathrm{Ni}, \mathrm{Cu}, \mathrm{Cr}, \mathrm{Ti}, \mathrm{Zn}, \mathrm{Mo}$, \\
Alkali / Alkali Earth Metal & $\mathrm{Na}, \mathrm{Al}, \mathrm{K}, \mathrm{Ca}$ \\
\hline
\end{tabular}

Additional relevant elements shown in the literature to have an impact [13-18], but they are without specifications in existing PV industry standards (i.e. SEMI PV 017 standards) are shown in Table 2.

Table 2. Elements that are impurities but have no specifications in existing industrial standards

\begin{tabular}{ll}
\hline Impurity Type & Element \\
\hline Acceptor & $\mathrm{In}, \mathrm{Ga}$ \\
Transition metals & $\mathrm{Co}, \mathrm{W}, \mathrm{Nb}, \mathrm{Au}, \mathrm{Zr}, \mathrm{V}, \mathrm{Mn}$ \\
Alkali / Alkali Earth Metal & $\mathrm{Mg}$ \\
\hline
\end{tabular}

\subsection{Processes}

\subsubsection{Metallurgical Grade Silicon (MG-Si)}

The methods for preparation of MG-Si, carbon and aluminum reduction are described in the following sections. Both have been implemented in the industry. However, because aluminum reduction produces a higher percentage of metallic impurities in the metallurgical material, carbon reduction has come to be the "process of choice" for producing MG silicon.

\subsubsection{Carbon Reduction}

MG-Si with a purity of $98-99 \%$ can be prepared by the reaction of high-purity silica with wood, charcoal, and coal in an electric arc furnace with graphite electrode (Eq.1). Silicon carbide (SiC) can form during this process, however, by keeping the amount of $\mathrm{SiO}_{2}$ high, $\mathrm{SiC}$ can be eliminated (Eq.2).

$$
\begin{array}{lll}
\mathrm{SiO}_{2}+2 \mathrm{C} \rightarrow \mathrm{MG}-\mathrm{Si}+2 \mathrm{CO} & \Delta \mathrm{H}=+680.70 \mathrm{~kJ} / \mathrm{mol} & \text { Eq. } 1 \\
2 \mathrm{SiC}+\mathrm{SiO}_{2} \rightarrow 3 \mathrm{MG}-\mathrm{Si}+2 \mathrm{CO} & \Delta \mathrm{H}=+820.30 \mathrm{~kJ} / \mathrm{mol} & \text { Eq. } 2
\end{array}
$$

MG-Si is contaminated with trace elements of metals such as $\mathrm{Fe}, \mathrm{Al}, \mathrm{Ti}, \mathrm{V}, \mathrm{B}$, and $\mathrm{P}$ and compounds like $\mathrm{SiC}, \mathrm{SiN}$, and $\mathrm{SiO}_{2}$, for example [19]. One of the main parameters, affecting the final yield of carbothermic process, is the quality of quartz raw material. Quartz is a naturally occurring mineral whos quality depends on the geographical location. Quartz material has to meet certain requirements to be 
accepted for use in feedstock production regarding its chemistry, chunk size, mechanical strength, thermal strength, and softening properties [20]. Quartz contains impurities such as Al, Ti, B, P, Ca, and $\mathrm{Fe}$, and inductively couple plasma-mass spectroscopy (ICP-MS) has been the method of choice for characterization of these impurities [20]. In general, the chunk size varies between $10-150 \mathrm{~mm}$. The appearance of the raw material is tested macroscopically (size, color), microscopically (impurities, crystal structure, defects), by fluorescent light (microcracks), and cathodoluminescence (CL) microscopy (source material) [20]. Thermo-mechanical and mechanical properties of quartz are explored using the Elkem method (measuring heat, thermal strength, friability, and dust indices), the Spigerverket method (not common), and the Brazilian test for thermal stability [20].

\subsubsection{Aluminum Reduction}

The reduction of silica $\left(\mathrm{SiO}_{2}\right)$ by aluminum is a highly exothermic process (Eq. 3 ) and the heat of the reaction is adequate to sustain the reaction without any additional energy input. However, after formation of alumina $\left(\mathrm{Al}_{2} \mathrm{O}_{3}\right)$, and in the presence of silica, the possibility of two side reactions exists, presented in Eqs. 4 and 5 (Note: The enthalpies are at 298K unless otherwise noted. As a result of this mixed temperatures, some enthalpies are not reported).

$$
\begin{array}{lll}
3 \mathrm{SiO}_{2}+4 \mathrm{Al} \rightarrow 2 \mathrm{Al}_{2} \mathrm{O}_{3}+3 \mathrm{MG}-\mathrm{Si} & \Delta \mathrm{H}=-619.3 \mathrm{~kJ} / \mathrm{mol} & \text { Eq.3 } \\
3 \mathrm{Al}_{2} \mathrm{O}_{3}+2 \mathrm{SiO}_{2} \rightarrow \mathrm{Al}_{6} \mathrm{Si}_{2} \mathrm{O}_{13} & \Delta \mathrm{H}_{1473 \mathrm{~K}}=-54.4 \mathrm{~kJ} / \mathrm{mol} & \text { Eq.4 } \\
8 \mathrm{Al}+\mathrm{Al}_{6} \mathrm{Si}_{2} \mathrm{O}_{13} \rightarrow 13 \mathrm{Al}_{2} \mathrm{O}_{3}+6 \mathrm{MG}-\mathrm{Si} & & \text { Eq.5 }
\end{array}
$$

The formation of mullite $\left(\mathrm{Al}_{6} \mathrm{Si}_{2} \mathrm{O}_{13}\right)$ and $\mathrm{Al}_{2} \mathrm{O}_{3}$ in these side reactions can be considered as yield reducers for SoG-Si production, as these minerals are not suitable for acid leaching .

\subsubsection{Upgraded Metallurgical Grade Silicon (UMG-Si)}

UMG-Si is MG-Si that has been further purified; but not quite to purity levels achieved with EG processes. The idea is to further improve metallurgical processes to achieve an acceptable purity level for the production of PV module and therefore avoid the need for costly chemical purification processes. When silicon feedstock (or polysilicon) has an acceptable purity level for the production of PV module, it is referred to as solar grade silicon (SoG-Si). SoG-Si is generally less pure than the polysilicon used for the electronics industry. The average reported energy consumption for UMG-Si is $30-40 \mathrm{kWh} / \mathrm{Kg}$ and average purity of $6 \mathrm{~N}$. The following sections describe several known UMG-Si manufacturing processes.

\subsubsection{Elkem Process}

The Elkem process has been mainly developed to reduce energy consumption, investment, and production costs of Si production. SoG-Si production via the Elkem process is a five step process that involves pyrometallurgical refining by adding calcium containing compound to molten silicon. These steps are: (1) smelter for MG-Si production; (2) slag treatment to remove $B$; (3) leaching by acids to reduce $\mathrm{P}$ and other metallic impurities; (4) directional solidification for further removal of impurities; and (5) post treatment by cleaning the bricks with acids. At the laboratory scale, the Elkem process consumes $25-30 \mathrm{kWh} / \mathrm{kg}$ energy. 


\subsubsection{Direct Carbothermic Reduction Process}

Production of SoG-Si using the direct carbothermic reduction process has been pursued by projects such as SOLSILC and SPURT. This process uses plasma as the heating source for silicon reduction, followed by a unidirectional solidification. It requires ultrapure quartz and carbon black and it consumes four times less energy than the Siemens process, i.e. $25-30 \mathrm{kWh} / \mathrm{kg}$ of the product. One drawback of this process is the residual carbon in the final product originating from the reduction process [22].

\subsubsection{Electrolysis Process}

Since 2002, Chisso Corporation and NEDO have been actively engaged in research and development of Chisso SoG-Si (CSS), in which $\mathrm{SiCl}_{4}$ undergoes an electrolytic reduction by zinc to produce $6 \mathrm{~N}$ grade polysilicon (Eq. 6) [22].

$\mathrm{SiCl}_{4}(\mathrm{~g})+2 \mathrm{Zn} \rightarrow \mathrm{Si}+2 \mathrm{ZnCl}_{2}(\mathrm{~g}) \quad \Delta \mathrm{H}=+124.8 \mathrm{~kJ} / \mathrm{mol} \quad$ Eq. 6

In another approach, quartz is dissolved in HF followed by deposition of silicon on an electrode. The advantages of this approach are the elimination of carbon, lower process temperature, and deposition of very pure silicon from highly contaminated dissolved silicon [22].

\subsubsection{4 $\mathrm{SiF}_{4}-\mathrm{Na}$ Process}

SoG-Si production via $\mathrm{SiF}_{4}$-Na process was developed by SRI International. In this process, a source of $\mathrm{Na}$ ions ( $\mathrm{NaF}$ ) is added to $\mathrm{H}_{2} \mathrm{SiF}_{6}$ aqueous solution to form $\mathrm{Na}_{2} \mathrm{SiF}_{6}$ (Eq. 7). Thermal decomposition of $\mathrm{Na}_{2} \mathrm{SiF}_{6}$ yields $\mathrm{SiF}_{4}$ and $\mathrm{NaF}$, which is recycled back to the first step (Eq. 8). Through a melting or leaching process, the $\mathrm{SiF}_{4}$ is reacted with $\mathrm{Na}$ to produce silicon and $\mathrm{NaF}$ (Eq. 9). A yield reducing parameter in this process is related to the formation of $\mathrm{Si}-\mathrm{O}$ bond during thermal decomposition of $\mathrm{Na}_{2} \mathrm{SiF}_{6}$, yielding solids such as $\mathrm{SiO}_{2}$ or $\mathrm{Na}_{2} \mathrm{SiF}_{\mathrm{n}}(\mathrm{OH})_{6-n}$. These solids trap impurities and hence reduce the purity of the generated $\mathrm{SiF}_{4}[23]$.

$\mathrm{H}_{2} \mathrm{SiF}_{6}+\mathrm{NaF} \rightarrow \mathrm{Na}_{2} \mathrm{SiF}_{6} \quad$ Eq. 7

$\mathrm{Na}_{2} \mathrm{SiF}_{6} \rightarrow \mathrm{SiF}_{4}+\mathrm{NaF} \quad$ Eq. 8

$\mathrm{SiF}_{4}+4 \mathrm{Na} \rightarrow \mathrm{Si}+4 \mathrm{NaF} \quad \Delta \mathrm{H}=-691.4 \mathrm{~kJ} / \mathrm{mol} \quad$ Eq. 9

\subsubsection{Directional Solidification (DS)}

The DS technique takes advantage of silicon's higher solubility of most impurities in its liquid state as compared to its the solid state. Using this approach, the uniformly distributed impurities will redistribute during the solidification process due to a majority of the impurities remaining in liquid phase and the solid silicon will be purified. Because $\mathrm{P}$ and $\mathrm{B}$ tend to be captured at grain boundaries, their removal from silicon using DS is almost impossible and hence other purification techniques have to be used. The size and crystallographic orientation of grains are important properties resulting from the solidification process. In situ and real-time X-ray imaging has been used to collect information on the grain structure and defects [24]. These methods can possibly play a role in the real-time control of the before-mentioned properties to improve both performance and reliability. 


\subsubsection{Electron Beam Melting}

The State University of Campinas (UNICAMP) has been researching and developing a purification technique of MG-Si using an electron beam melting approach. The advantages of this technique are that their vapor pressures are higher than silicon and the use of a refrigerated copper crucible. The purity of final product has been reported to be $99.9995 \%$, with B as the only element with the lowest extraction efficiency [22].

\subsubsection{Photosil Process}

An alternative approach to MG-Si purification is the Photosil process. In this process, metal impurities and $\mathrm{P}$ are removed by subjecting the liquid MG-Si to two consecutive segregation treatments. The first segregation process reduces the metal impurities and $\mathrm{P}$ concentration to result in a so-called UMG-1 (i.e., first treatment). The UMG-1 is then remelted and subjected to the secondary segregation process in which elements with small segregation coefficient are removed during solidification, resulting in solid UMG-2 silicon. The obtained UMG-2 solid silicon undergoes a plasma purification process in which the reactive species within an $\mathrm{Ar}$ plasma gas are able to volatilize impurities with large segregation coefficients such as B, C, Al, etc. An in-line ICP-OES (optical emission spectroscopy) is used to monitor the concentrations of elements such as $B$ and $P$ in the exhaust gas [25].

\subsubsection{NEDO melt-purification Process}

The NEDO melt-purification process of MG-Si involves a two stage process. The first stage consists of the removal of $\mathrm{P}$ and metallic impurities by directional solidification using electron beam equipment. For the second stage, B and C removal is carried out via plasma melting followed by a final metallic impurity removal by directional solidification [26].

\subsubsection{Recycled Kerf loss Silicon}

The total waste of high purity silicon during wafer slicing is greater than $40 \%$. This kerf silicon loss contains silicon carbide and metals from the saw wire. Effective recycling techniques need to be developed as these particles are in $\mu \mathrm{m}$ and sub- $\mu \mathrm{m}$ ranges and, therefore, are hard to remove. Recently, Wang et al. reported a recycling technique based on nitric acid treatment to dissolve the metals followed by centrifugation to remove SiC [27]. The overall recycling yield was reported to be $45 \%$.

\subsubsection{Electronic Grade (EG)}

EG-Si is mainly produced using the Siemens and Fluidized Bed processes, although other processes are discussed below. At first, scraps of EG-Si were used as the main feedstock route for SoG-Si. This was true before 2003 when total demand for SoG-Si was less than 10,000 tons/year. By 2005, the amount of EG scrap could not supply the demand for SoG-Si, so many companies started polysilicon production to meet the demand for PV [28]. Although EG-Si has the highest level of purity and hence capable of achieving close to theoretical efficiency (29\%), its high cost/area and high processing-energy demand have been the main drawbacks. Therefore, over the past three decades, a great amount of research effort has been dedicated on finding lower cost processes for polysilicon production. 
The four most-used polysilicon feedstocks for the production of EG-Si are silane $\left(\mathrm{SiH}_{4}\right)$, dichlorosilane (DCS, $\mathrm{SiH}_{2} \mathrm{Cl}_{2}$ ), trichlorosilane ( $\mathrm{TCS}, \mathrm{SiHCl}_{3}$ ), and silicon tetrachloride (STC, $\mathrm{SiCl}_{4}$ ). Currently, $\mathrm{TCS}$, prepared from MG-Si, is the prevalent feedstock because of its favorable balance of manufacturing, purification, handling, and chemical reduction properties.

\subsubsection{Historical Perspective}

\subsection{0's}

Siemens Process (Bell jar reactor). In the late 1950's the only two silicon purification processes in production were the Siemens process (leading) and the Komatsu process. Production of c-Si wafers, with high efficiency, requires high purity material. In the Siemens process, MG-Si is first reacted with hydrochloric acid to form trichlorosilane (Eq. 10). The distillation of TCS allows for most of the impurities to be separated. Using a batch process, inside a Siemens reactor, TCS is converted to solid polysilicon via a growth process on the surface of silicon filaments. The growth process is activated by high temperatures $\left(\approx 1150^{\circ} \mathrm{C}\right)$, which allows for the hydrogenation of the TCS and production of $\mathrm{HCl}$ as a catalyst. Eq. 11 shows the reaction of TCS conversion to polysilicon.

$$
\begin{array}{lll}
\mathrm{MG}-\mathrm{Si}+3 \mathrm{HCl} \rightarrow \mathrm{SiHCl}_{3}+\mathrm{H}_{2} & \Delta \mathrm{H}=-236.1 \mathrm{~kJ} / \mathrm{mol} & \text { Eq. } 10 \\
4 \mathrm{SiHCl}_{3}+2 \mathrm{H}_{2} \rightarrow 3 \mathrm{Si}+\mathrm{SiCl}_{4}+8 \mathrm{HCl} & \Delta \mathrm{H}=+656.6 \mathrm{~kJ} / \mathrm{mol} & \text { Eq. } 11
\end{array}
$$

The Siemens process is highly energy consuming, with a major part of the energy being dispersed and lost. To avoid deposition on the inner surfaces of the reaction chamber, the walls have to be cooled and, therefore, up to $90 \%$ of the energy is wasted on the reactor walls. Currently, there are 13 global suppliers using the Siemens process. Major producers are Hemlock, Wacker, REC, GCL, Tokuyama, OCl and Mitsubishi.

DuPont Process (Fluidized bed reactor). The DuPont process was in pilot production at Texas Instruments and lab testing at MEMC. The DuPont process involves reduction of tetrahalosilane $\left(\mathrm{SiX}_{4}\right)$ or trihalosilane $\left(\mathrm{SiHX}_{3}\right)$ (where $\mathrm{X}$ could be chlorine, bromine or iodine) with $\mathrm{H}, \mathrm{Zn}$ or $\mathrm{Cd}$ in a fluid or moving bed reactor. The process resulted in the formation of large quantities of amorphous silicon dust and explosive polymers when in contact with chlorosilanes.

lodide Process (Seed particle or heated filament). The lodide process was a lab study and has never gone into production. The production of silicon by using iodide process starts with a reaction between unpurified $\mathrm{Si}$ and I to form silicon tetraiodide $\left(\mathrm{Sil}_{4}\right)$ (Eq. 12) followed by purification (Eqs 13, 14) of tetraiodide via recrystallization, distillation and, finally, decomposition to high-purity elemental silicon and iodine $[29,30]$.
$4 \mathrm{I}+\mathrm{Si}_{(\text {(unpurified) }} \rightarrow \mathrm{Si}_{4}$
$\Delta \mathrm{H}=-189.5 \mathrm{~kJ} / \mathrm{mol}$
Eq. 12
$\mathrm{Sil}_{4} \rightarrow \mathrm{Sil}_{2}+2 \mathrm{I}$
Eq. 13
$\mathrm{Sil}_{2} \rightarrow \mathrm{Si}($ pure) $+2 \mathrm{I}$
Eq. 14

Komatsu Process (Bell jar reactor). The Komatsu process uses silane $\left(\mathrm{SiH}_{4}\right)$ in a Siemens-like bell jar reactor, rather than the TCS of the Siemens process. Komatsu would later acquire the Union Carbide 
Corporation and combine their low cost silane ion-exchange separation of the union carbide process with its reactor technology.

\subsection{0's}

In the 1970's, new silicon purification methods were introduced. Among these were the Union Carbide process and the Schumacher process.

Union Carbide Process (Free space reactor). The Union Carbide process is another approach that uses silane. It relies on a low cost silane ion-exchange separation of silane to be reacted in a free space reactor with subsequent consolidation via melting. But the free space/melting approach proved impractical. The use of $\mathrm{SiH}_{4}$ as a feed allows for lower operational temperatures, higher conversion efficiency, and the elimination of corrosive byproducts [31].

Schumacher Process (Fluidized bed reactor). In the Schumacher process, the chlorinated silane or monosilane of Siemens and fluidized bed reactor (FBR) processes are replaced by brominated silane. Significantly lower processing temperatures in a continuous loop rather than a batch process have been recognized as the main advantages of Schumacher approach [32].

\subsection{0’s}

The 1980's saw a significant push for the fluidized bed processes in order to produce EG-Si faster and cheaper without sacrificing the purity. The JC Schumacher Company continued working on its promising Fluid Bed Reactor process based on tribromosilane. Texas Instruments also continued to develop a TCS fluid bed process during the 80 's although the initial effort took place in the 60's.

Ethyl Corporation Process (Fluidized bed reactor). The Ethyl Corporation started to develop a Silane based Fluidized Bed Reactor (FBR) EG-Si process. Also referred to as the MEMC process today, this is a silicon purification approach in a sub-ppb range used for EG-Si. In this process, hexafluorosilicic acid $\left(\mathrm{H}_{2} \mathrm{SiF}_{6}\right)$ is reacted with sodium aluminum hydride $\left(\mathrm{NaAlH}_{4}\right)$ to produce silane (Eq. 15). The produced silane is then decomposed (dehydrogenation, Eq. 16) in a FBR to Si and $\mathrm{H}$ [33]. The main yield reducing issues for the Ethyl Corporation process are reported to be the generation of fine powder and $\mathrm{H}$ adsorption into the polysilicon deposition layer [31].

$\mathrm{H}_{2} \mathrm{SiF}_{6}+\mathrm{NaAlH}_{4} \rightarrow \mathrm{SiH}_{4}+\mathrm{NaAlF}_{6} \quad$ Eq. 15

$\mathrm{SiH}_{4} \rightarrow \mathrm{Si}+2 \mathrm{H}_{2} \quad \Delta \mathrm{H}=-34.3 \mathrm{~kJ} / \mathrm{mol} \quad$ Eq. 16

$\mathrm{H}$ adsorption is the result of a low FBR decomposition temperature unable to break the more stable $\mathrm{Si}-\mathrm{H}$ bonds. Consequently, when the hydrogen is released during melting, $\mathrm{Si}$ is splattered on the crucible and hot zone. The splatter can become a source of particles that later can cause loss of a dislocation free structure during crystal growth. Hydrogen can be significantly reduced by baking prior to melting.

\subsubsection{Today's Methods of Choice}

\subsection{TCS Siemens Processes}

Siemens CVD reactors have significantly evolved over time. Productivity has improved because of increased reactor size and pressure. A positive byproduct of increasing both the pressure and size of the 
reactor has been significant decreasing electrical power consumption. As the demand for polysilicon grew, TCS capacity was increased specifically to support the polysilicon demand. Eventually, as the supply of silicon tetrachloride (STC), a by-product of the Siemens process, exceeded its demand, processes to make TCS from STC were developed. Two dominant technologies were developed to deal with the STC oversupply: STC converters (hydrogenation) and HydroChlorination (HC). Recently, STC is also being converted to high-purity silica.

\subsection{TCS Siemens with STC Converters or Hydrogenation}

The basic technology of STC converters is the hydrogenation of STC at $\sim 1000{ }^{\circ} \mathrm{C}$ by the following reaction:

$$
3 \mathrm{H}_{2}+\mathrm{SiCl}_{4} \rightarrow \mathrm{HSiCl}_{3}+3 \mathrm{HCl} \quad \Delta \mathrm{H}=+51.7 \mathrm{~kJ} / \mathrm{mol} \quad \text { Eq. } 17
$$

STC converters traditionally represented more production capacity than $\mathrm{HC}$ in the period from 1985 to 2005. Both technologies are being built into new facilities, but HC has become much more prevalent since about 2004.

\subsection{TCS Siemens with HydroChlorination (HC)}

The average reported energy consumption for TCS Siemens HC is $90-110 \mathrm{kWh} / \mathrm{Kg}$ for a purity of 9-11N. However, purity ranges from $6 \mathrm{~N}$ to $11 \mathrm{~N}$ depending on the supplier and the purification technology, experience in operation and investment in quality assurance and quality control methods. The experienced major suppliers can currently supply $11 \mathrm{~N}$ for PV applications. $\mathrm{HC}$ is a continuous process where STC and hydrogen are contacted with MG-Si to form TCS at reaction temperatures typically $>500$ ${ }^{\circ} \mathrm{C}$ and pressures $>20$ bar:

$$
3 \mathrm{SiCl}_{4}+\mathrm{Si}+2 \mathrm{H}_{2} \rightarrow 4 \mathrm{HSiCl}_{3} \quad \Delta \mathrm{H}=-81 \mathrm{~kJ} / \mathrm{mol} \quad \mathrm{Eq} .18
$$

The HC process is continuous and can operate a long time between shutdowns (more than a year). This is possible because impurities in the MG-Si become volatile and leave as gaseous reactor waste during the generation of TCS.

\subsection{TCS Siemens with Direct Chlorination (DC)}

The average reported energy consumption for TCS Siemens DC is $140 \mathrm{kWh} / \mathrm{Kg}$ and average purity of $9 \mathrm{~N}$. Similarly to HC, purity levels vary greatly and experienced major suppliers can deliver $11 \mathrm{~N}$ using DC. This process is normally carried out in a DC FBR where finely ground MG-Si is reacted with $\mathrm{HCl}$ gas at about $300{ }^{\circ} \mathrm{C}$ and $2-4$ barG. TCS is then purified by distillation steps.

$$
\mathrm{Si}+3 \mathrm{HCl} \rightarrow \mathrm{HSiCl}_{3}+\mathrm{H}_{2} \quad \Delta \mathrm{H}=-236.1 \mathrm{~kJ} / \mathrm{mol} \quad \text { Eq.19 }
$$

The DC process results in impurities accumulating in the FBR and thus requires bed dumps every 6-10 weeks.

\subsection{TCS Siemens with Pyrogenic Silica Production}

The basic technology being pyrogenic silica production is to heat up STC in the presence of oxygen and hydrogen by the following reaction:

$$
\mathrm{SiCl}_{4(\mathrm{~g})}+2 \mathrm{H}_{2}+\mathrm{O}_{2} \rightarrow \mathrm{SiO}_{2(\mathrm{~g})}+4 \mathrm{HCl} \quad \Delta \mathrm{H}=-34.2 \mathrm{~kJ} / \mathrm{mol} \quad \text { Eq.20 }
$$


The produced silica can be recycled and used in the production of silicon while the $\mathrm{HCl}$ can be added to the DC FBR reactors to make TCS. It must be noted that using $\mathrm{SiO}_{2}$ in the FBR reactor is not practical unless the $\mathrm{SiO}_{2}$ is produced as granules of specific size rather than an amorphous powder.

Table 3. Comparison of the energy density for various TCS Siemens Processes

\begin{tabular}{lll}
\hline Method & Reaction Pathways & kWh/kg \\
\hline Hydrogenation & $3 \mathrm{H}_{2}+\mathrm{SiCl}_{4} \rightarrow \mathrm{HSiCl}_{3}+3 \mathrm{HCl}$ & - \\
HydroChlorination & $3 \mathrm{SiCl}_{4}+\mathrm{Si}+2 \mathrm{H}_{2} \rightarrow 4 \mathrm{HSiCl}$ & $90-110$ \\
Direct Chlorination & $\mathrm{Si}+3 \mathrm{HCl} \rightarrow \mathrm{HSiCl}_{3}+\mathrm{H} 2$ & 140 \\
Pyrogenic Silica & $\mathrm{SiCl}_{4}+2 \mathrm{H}_{2}+\mathrm{O}_{2} \rightarrow \mathrm{SiO}_{2}+4 \mathrm{HCl}$ & - \\
\hline
\end{tabular}

\subsection{Silane Siemens}

This upgraded version of Komatsu process produces the highest purity EG polysilicon today, $9 \mathrm{~N}$ or more, with an average energy consumption of $157 \mathrm{kWh} / \mathrm{kg}$. Initially, in the Komatsu method, high quality silane was obtained via the reaction of magnesium with MG-Si together at $500{ }^{\circ} \mathrm{C}$ in a hydrogen atmosphere to produce magnesium silicide $\left(\mathrm{Mg}_{2} \mathrm{Si}\right)$. Then $\mathrm{Mg}_{2} \mathrm{Si}$ was made to react with ammonium chloride $\left(\mathrm{NH}_{4} \mathrm{Cl}\right)$ in liquid ammonia under $0{ }^{\circ} \mathrm{C}$ to make silane $\left(\mathrm{SiH}_{4}\right)$. This magnesium silicide process by Komatsu was terminated when production of silane by the HydroChlorination process was implemented at Union Carbide Corp in 1985. The magnesium silicide process was dropped because of higher cost and small production volume.

EG-Si can be then produced by the decomposition of silane via pyrolysis at $700-800{ }^{\circ} \mathrm{C}$ according to the following reaction:

$$
\mathrm{SiH}_{4} \rightarrow \mathrm{Si}+2 \mathrm{H}_{2} \quad \Delta \mathrm{H}=-34.2 \mathrm{~kJ} / \mathrm{mol} \quad \text { Eq.21 }
$$

\subsection{Silane Fluidized Bed Reactor Process (FBR)}

Polysilicon particles are produced by fluidizing silicon seed particles in a cone shaped reactor at a temperature above the decomposition temperature of a precursor gas, typically $\mathrm{SiH}_{4}$. When particles reach a critical weight, they lose their upward drag force and settle at the bottom of the reactor. Polysilicon is also produced via the pyrolysis of silane (see Eq. 21). The FBR has an overall greater efficiency in use of reactant gases and at about $12-20 \mathrm{kWh} / \mathrm{kg}$ is less energy intensive with an average purity of $8 \mathrm{~N}$. REC boasted $4.1 \mathrm{KWh} / \mathrm{kg}$ in a 2012 Q1 report. However, temperature control between the reactant zone and the walls of the reactor is one of the main challenges of this process. Both MEMC (SunEdison) and REC produce polysilicon using Silane FBR technology.

\subsection{TCS Fluidized Bed Reactor Process (FBR)}

TCS FBR is also a lower energy process compared to Siemens. The deposition process relies on the following reactions:

$$
\begin{array}{lll}
\mathrm{SiHCl}_{3}+\mathrm{H}_{2} \rightarrow \mathrm{Si}+3 \mathrm{HCl} & \Delta \mathrm{H}=+236.1 \mathrm{~kJ} / \mathrm{mol} & \text { Eq.22 } \\
4 \mathrm{SiHCl}_{3} \rightarrow 2 \mathrm{H}_{2}+3 \mathrm{SiCl}_{4}+\mathrm{Si} & \Delta \mathrm{H}=+81 \mathrm{~kJ} / \mathrm{mol} & \text { Eq.23 }
\end{array}
$$


Wacker, KRICT, AEP, SILIKEN are reported to experiment with TCS FBR polysilicon.

\subsection{TBS Fluidized Bed Reactor Process (FBR)}

The process begins by reacting metallurgical grade MG silicon with hydrogen and silicon tetrabromide $\left(\mathrm{SiBr}_{4}\right)$ to form a mixture of $\mathrm{SiBr}_{4}$ and tribromosilane $\left(\mathrm{SiHBr}_{3}\right)$ which is separated and purified by distillation. The silicon deposition takes place according to the following reaction:

$$
4 \mathrm{SiHBr}_{3} \rightarrow \mathrm{Si}+3 \mathrm{SiBr}_{4}+2 \mathrm{H}_{2} \quad \Delta \mathrm{H}=+23.9 \mathrm{~kJ} / \mathrm{mol} \quad \mathrm{Eq} .24
$$

\subsubsection{Summary of Impurity Levels for Various Silicon Feedstock Routes}

Tables 4 and 5 show the accepted, specified, and achieved levels of impurities for SoG, UMG, and EG-Si from various feedstock routes, respectively.

Table 4. Accepted, specified, and achieved levels of impurities for SoG-Si from various feedstock routes

\begin{tabular}{|c|c|c|c|c|c|c|c|c|}
\hline \multirow[b]{2}{*}{ 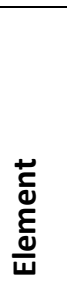 } & \multirow[b]{2}{*}{ 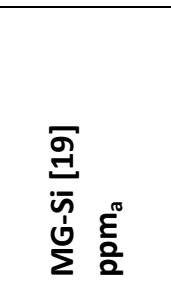 } & \multicolumn{3}{|c|}{$\begin{array}{l}\text { Acceptable levels [34] } \\
\text { ppm }_{\mathrm{a}}\end{array}$} & \multicolumn{4}{|c|}{ SoG-Si (SEMI PV 017-0611) } \\
\hline & & $\sum_{\substack{0 \\
\vdots}}^{0}$ & $\frac{\grave{\varpi}}{\frac{\pi}{\pi}}$ & 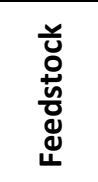 & $\begin{array}{l}\overline{8} \\
\frac{\pi}{50} \\
\text { iv }\end{array}$ & $\begin{array}{l}= \\
0 \\
\frac{0}{0} \\
\frac{\pi}{0}\end{array}$ & $\begin{array}{l}\equiv \\
0 \\
\frac{\pi}{0} \\
0\end{array}$ & $\begin{array}{l}\geq \\
\frac{0}{0} \\
\frac{0}{0} \\
0\end{array}$ \\
\hline $\mathrm{Al}$ & $1200-4000$ & & & & $<1 \mathrm{ppb}_{\mathrm{a}}$ & $<20 \mathrm{ppb}_{\mathrm{a}}$ & $<300 \mathrm{ppb}_{\mathrm{a}}$ & $<1000 \mathrm{ppb}_{\mathrm{a}}$ \\
\hline $\mathrm{B}$ & $37-45$ & & & & $<1 \mathrm{ppb}_{\mathrm{a}}$ & $<20 \mathrm{ppb}_{\mathrm{a}}$ & $<300 \mathrm{ppb}_{\mathrm{a}}$ & $<1000 \mathrm{ppb}_{\mathrm{a}}$ \\
\hline$P$ & $27-30$ & & & & $<1 \mathrm{ppb}_{\mathrm{a}}$ & $<20 \mathrm{ppb}_{\mathrm{a}}$ & $<50 \mathrm{ppb}_{\mathrm{a}}$ & $<720 \mathrm{ppb}_{\mathrm{a}}$ \\
\hline $\mathrm{Ca}$ & 590 & & & & $<10 \mathrm{ppb}_{\mathrm{a}}$ & $<50 \mathrm{ppb}_{\mathrm{a}}$ & $<100 \mathrm{ppb}_{\mathrm{a}}$ & $<4000 \mathrm{ppb}_{\mathrm{a}}$ \\
\hline $\mathrm{K}$ & & & & & $<10 \mathrm{ppb}_{\mathrm{a}}$ & $<50 \mathrm{ppb}_{\mathrm{a}}$ & $<100 \mathrm{ppb}_{\mathrm{a}}$ & $<4000 \mathrm{ppb}_{\mathrm{a}}$ \\
\hline $\mathrm{Na}$ & & & & & $<10 \mathrm{ppb}_{\mathrm{a}}$ & $<50 \mathrm{ppb}_{\mathrm{a}}$ & $<100 \mathrm{ppb}_{\mathrm{a}}$ & $<4000 \mathrm{ppb}_{\mathrm{a}}$ \\
\hline $\mathrm{Cr}$ & $50-140$ & $\begin{array}{l}4.7 \cdot 10 \\
-4\end{array}$ & $4.8 \mathrm{E}-4$ & 0.026 & $<10 \mathrm{ppb}_{\mathrm{a}}$ & $<50 \mathrm{ppb}_{\mathrm{a}}$ & $<100 \mathrm{ppb}_{\mathrm{a}}$ & $<200 \mathrm{ppb}_{\mathrm{a}}$ \\
\hline $\mathrm{Cu}$ & $24-90$ & $5.9 \mathrm{E}-3$ & 0.046 & 4.6 & $<10 \mathrm{ppb}_{\mathrm{a}}$ & $<50 \mathrm{ppb}_{\mathrm{a}}$ & $<100 \mathrm{ppb}_{\mathrm{a}}$ & $<200 \mathrm{ppb}_{\mathrm{a}}$ \\
\hline $\mathrm{Fe}$ & $1600-3000$ & $9.7 \mathrm{E}-3$ & 0.010 & 12.5 & $<10 \mathrm{ppb}_{\mathrm{a}}$ & $<50 \mathrm{ppb}_{\mathrm{a}}$ & $<100 \mathrm{ppb}_{\mathrm{a}}$ & $<200 \mathrm{ppb}_{\mathrm{a}}$ \\
\hline $\mathrm{Mn}$ & $70-80$ & & & & & & & \\
\hline Mo & $<10$ & & & & $<10 \mathrm{ppb}_{\mathrm{a}}$ & $<50 \mathrm{ppb}_{\mathrm{a}}$ & $<100 \mathrm{ppb}_{\mathrm{a}}$ & $<200 \mathrm{ppb}_{\mathrm{a}}$ \\
\hline$Z n$ & & & & & $<10 \mathrm{ppb}_{\mathrm{a}}$ & $<50 \mathrm{ppb}_{\mathrm{a}}$ & $<100 \mathrm{ppb}_{\mathrm{a}}$ & $<200 \mathrm{ppb}_{\mathrm{a}}$ \\
\hline $\mathrm{Ni}$ & $40-80$ & & & & $<10 \mathrm{ppb}_{\mathrm{a}}$ & $<50 \mathrm{ppb}_{\mathrm{a}}$ & $<100 \mathrm{ppb}_{\mathrm{a}}$ & $<200 \mathrm{ppb}_{\mathrm{a}}$ \\
\hline $\mathrm{Ti}$ & $150-200$ & $2.7 \mathrm{E}-4$ & $2.7 \mathrm{E}-4$ & 0.022 & $<10 \mathrm{ppb}_{\mathrm{a}}$ & $<50 \mathrm{ppb}_{\mathrm{a}}$ & $<100 \mathrm{ppb}_{\mathrm{a}}$ & $<200 \mathrm{ppb}_{\mathrm{a}}$ \\
\hline $\mathrm{V}$ & $100-200$ & & & & & & & \\
\hline $\mathrm{Zr}$ & 30 & & & & & & & \\
\hline As & & & & & & $<20 \mathrm{ppb}_{\mathrm{a}}$ & $<50 \mathrm{ppb}_{\mathrm{a}}$ & $<720 \mathrm{ppb}_{\mathrm{a}}$ \\
\hline $\mathrm{Sb}$ & & & & & & $<20 \mathrm{ppb}_{\mathrm{a}}$ & $<50 \mathrm{ppb}_{\mathrm{a}}$ & $<720 \mathrm{ppb}_{\mathrm{a}}$ \\
\hline $\mathrm{C}$ & & & & & $<0.3 \mathrm{ppm}_{\mathrm{a}}$ & $<2 \mathrm{ppm}_{\mathrm{a}}$ & $<5 \mathrm{ppm}_{\mathrm{a}}$ & $<100 \mathrm{ppm}_{\mathrm{a}}$ \\
\hline $\mathrm{Mg}$ & & & & & & & & \\
\hline
\end{tabular}

Table 5. Accepted, specified, and achieved levels of impurities for UMG and EG silicon from various feedstock routes

\begin{tabular}{|l|l|l|}
\hline$\frac{0}{\amalg} \mathrm{E}$ & UMG - Si & EG - Si \\
\hline
\end{tabular}




\begin{tabular}{|c|c|c|c|c|c|c|c|c|c|c|}
\hline & 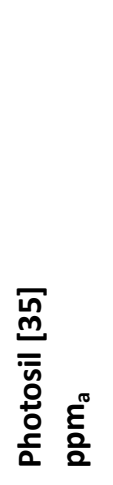 & 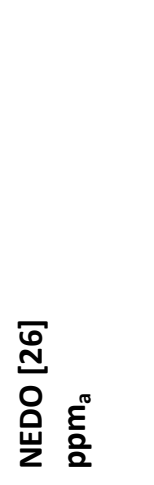 & 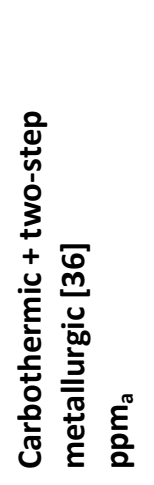 & 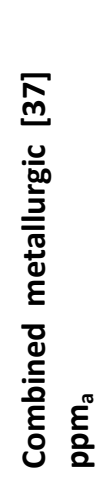 & 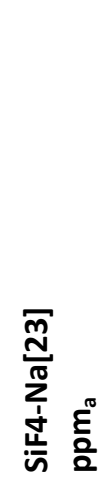 & 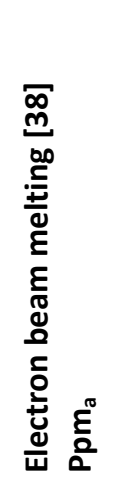 & 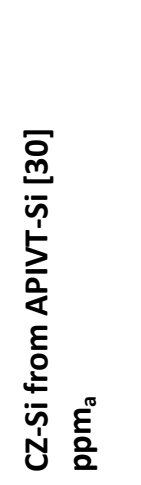 & 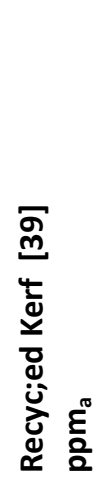 & 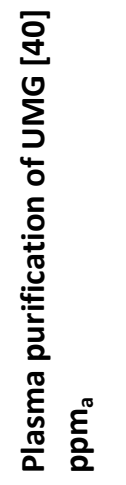 & 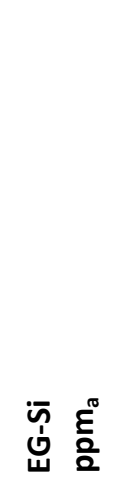 \\
\hline $\mathrm{Al}$ & $<2.1$ & $<0.01$ & $16.7 \pm 5$ & $<0.01$ & 0.14 & 0.44 & $<0.005$ & $<0.05$ & $<1.0$ & $<0.0008$ \\
\hline $\mathrm{B}$ & 0.79 & $0.11-0.21$ & $13 \pm 4$ & $<0.59$ & 0.08 & 19.2 & 4.16 & 1.28 & $1.3-5.3$ & $<0.0002$ \\
\hline$P$ & 0.91 & $0.03-0.13$ & $7.3 \pm 2$ & 0.06 & 0.05 & 0.35 & 6.80 & 1.54 & 9.1-18 & $<0.0008$ \\
\hline $\mathrm{Ca}$ & & & & $<0.07$ & & 0.22 & $<0.007$ & $<0.35$ & $<0.7$ & $<0.003$ \\
\hline $\mathrm{K}$ & & & & & & 0.007 & $<0.007$ & & & \\
\hline $\mathrm{Na}$ & & & & & & 0.06 & & & & \\
\hline $\mathrm{Cr}$ & & & $1.46 \pm 0.8$ & & 0.005 & & $<0.001$ & $<0.05$ & & $<0.003$ \\
\hline $\mathrm{Cu}$ & $<0.88$ & & $1.8 \pm 0.9$ & $<0.002$ & 0.004 & 0.13 & $<0.001$ & 1.1 & & $<0.003$ \\
\hline $\mathrm{Fe}$ & $<1$ & $<0.025$ & $13.6 \pm 4$ & $<0.03$ & 0.11 & 0.35 & $<0.005$ & $<0.025$ & $<0.5$ & $<0.01$ \\
\hline $\mathrm{Mn}$ & & & & & & 0.013 & $<0.001$ & & & $<0.003$ \\
\hline Mo & & & & & 0.00 & & $<0.001$ & & & $<0.003$ \\
\hline $\mathrm{Zn}$ & & & & & 0.07 & & $<0.002$ & $<0.02$ & & \\
\hline $\mathrm{Ni}$ & & & & & 0.00 & & $<0.002$ & 0.03 & & $<0.01$ \\
\hline $\mathrm{Ti}$ & $<1.17$ & $<0.006$ & $1.75 \pm 1$ & & 0.13 & 0.05 & $<0.001$ & $<0.006$ & $<0.29$ & $<0.003$ \\
\hline $\mathrm{V}$ & & & & & 0.00 & & $<0.001$ & & & $<0.003$ \\
\hline $\mathrm{Zr}$ & & & & & & & $<0.0003$ & & & \\
\hline As & & & & $<0.02$ & 0.00 & & $<0.002$ & & & \\
\hline \multicolumn{11}{|l|}{$\mathrm{Sb}$} \\
\hline $\mathrm{C}$ & & & & & & & 14.26 & & $23-35$ & \\
\hline $\mathrm{Mg}$ & & & & & 0.53 & 0.02 & $<0.001$ & $<0.06$ & & \\
\hline
\end{tabular}

\subsection{Reliability Challenges}

In this section, potential PV reliability challenges are discussed for the two current industry relevant processes: Siemens and Fluidized Bed.

\subsubsection{Impurities}

The main long-term PV reliability challenge that can be tied to feedstock production is related to impurities. We consider the following potential sources of contamination during feedstock production using the Siemens process:

- The graphite rods that are used in thermal converters are sources of carbon contamination, but these are being replaced by the HC.

- The graphite chucks used to secure the polysilicon seed rods to the electrical contact in the baseplate of the reactor can be sources of contamination. Contamination is easily avoided if the entire chuck is removed before processing the grown polysilicon rod. 
- Polysilicon seed rod sections that have been sawn or fabricated and used for the nucleation of TCS or silane gas and the resultant growth of a polysilicon rod can be a source of impurity. If so, chemical etching is used to remove surface contamination. In addition, advanced processing avoids sawing and grinding.

- The purity of TCS as well as the design of the TCS distillation and purification system.

- The unpassivated surfaces of tanks, valves, and pipes.

We consider the following potential sources of contamination during feedstock production using the FBR process:

- The failure of the reactor wall coating by cracking and spalling. Reactors are prepared by decomposing silane on SiC coated walls. The high purity Si coating works well as long as the SiC coating remains crack free and the Si coating does not spall.

- Metal contamination by repeated contact with reactor pipes, valves, and under seed production.

- Milling of granules for seed generation is another source of metal contamination [41].

\subsubsection{Particle size and distribution (FBR)}

Seeds and fine particles in FBR, due to their high surface areas, are more prone to oxidation, i.e. silicon dioxide contamination, and attraction of ambient elements such as carbon. The silicon dioxide solid particles are detrimental in the melt process as they cause dislocation formation. The multiplication and migration of these dislocations inhibit proper crystal growth [41]. The fine particles come from:

- Lack of surface stability for beads in TCS based fluidized reactors reducing silicon bonding to the surface and premature removal forming fine particles [42]

- Homogenous nucleation in silicon vapor, both from Silane or Trichlorosilane, produces vast quantities of sub $\mu \mathrm{m}$ diameter amorphous silicon dust $[42,43]$. However, with Tribromosilane (TBS) used in the Schumacher process, growth is favored over nucleation so that no submicron amorphous silicon dust is produced.

- Clogging of the volume above the bed, also known as freeboard, with fine particles can further increase fine particles production. This is due to low temperatures in this zone, therefore inhibiting reactant gas decomposition.

\subsubsection{Failure under operation}

Four to five percent of polysilicon produced is also rejected for quality reasons including failure under operation such as:

- Aborted runs because of power failure

- Hot spot formation and filament burn out

- Broken or imperfect seed rods

- Gas inclusions and to non-uniform deposition at the joints

- Impure TCS, impure hydrogen

- Powder deposition on rod surface or included in the growth layer

- Contamination during rod processing 


\subsection{Metrology Strategies}

\subsubsection{Existing Metrology Techniques}

Typical metrology carried out on feedstock prior to crystal growth consists primarily of elemental analysis. Impurity elements of interest were identified earlier in Tables 1 and 2. Available techniques to measure these impurities are [44]:

- $\quad$ Fourier Transform Infrared Spectroscopy (FTIR). FTIR provides interstitial O concentration and subsitutional $\mathrm{C}$ concentration. Low temperature FTIR or photoluminescence ( $\mathrm{PL}$ ) can provide $\mathrm{B}$, $\mathrm{P}$ and $\mathrm{Al}$ concentrations. FTIR cannot quantify $\mathrm{O}$ or $\mathrm{C}$ in precipitate form. Also, the reflectivity of the sample backside can introduce some error in the measurement.

- Neutron Activation Analysis (NAA). NAA is the most sensitive instrumental analysis technique and can make measurements on any form of feedstock. Unfortunately, results can take several months to obtain. Detection limits are not useful for dopant elements, which are usually present in high concentration.

- Inductively-Coupled Plasma Mass Spectrometry (ICPMS). ICPMS is useful to test for metals on the surface of any polysilicon form, such as chunks, granules, or powders. However, it is not able to measure the bulk impurity levels such as $\mathrm{P}, \mathrm{O}, \mathrm{C}$, and $\mathrm{N}$.

- Inert Gas Analysis (IGA) or Gas Fusion. IGA requires the feedstock to be shaped into a cylinder for insertion into the instrument. The sample is then heated such that gases $(O, C, N, H)$ from the sample are emitted and analyzed.

- Glow Discharge Mass Spectrometry (GDMS). GDMS techniques can be used to quantitatively measure any elemental impurity concentrations in $6 \mathrm{~N}$ pure (and higher) materials, in any form (wafers, chunks, granules, powder, etc). GDMS has poor detection limits for atmospheric species ( $\mathrm{O}, \mathrm{C}$ or N). It is most effectively used for the characterization of UMG-Si where a wide range of impurities are present. This is a direct sampling technique so there is no specialized sample preparation is required.

- Secondary Ion Mass Spectrometry (SIMS). SIMS is a fast and accurate technique that can measure all elements in any material form (wafer, chunks, granules, powder, etc), but is especially effective for dopants (B, P, As, Sb, Al, In), independent of electrical activity, and for atmospherics species $(\mathrm{H}, \mathrm{O}, \mathrm{C}, \mathrm{N})$, independent of their chemical state. This technique provides a more accurate quantitative measurement for impurities in SoG-Si at the sub-6N purity level. This is a direct sampling technique that does not require any specialized sample preparation.

Table 6. Comparison of the concentration limits for various elemental analysis techniques

\begin{tabular}{ll}
\hline Technique & Detection Limit \\
\hline FTIR & $100 \mathrm{ppm}$ \\
NAA & $10 \mathrm{ppb}$ \\
ICP-MS & $10 \mathrm{ppb}$ \\
IGA & $1 \mathrm{ppm}$ \\
GDMS & $10 \mathrm{ppt}$ \\
TOF-SIMS & $10 \mathrm{ppb}$ \\
Dynamic SIMS & $1 \mathrm{ppt}$ \\
\hline
\end{tabular}




\subsubsection{Metrology Techniques Beneficial for Reliability}

Of the available metrology techniques, direct sampling using GDMS or SIMS are the most sensitive analytical methods available today for routine analyses of SoG-Si materials [45]. Table 7 summarizes useful feedstock metrology techniques for increased module reliability.

Table 7. Useful metrology techniques during feedstock production for increased module performance and reliability

\begin{tabular}{|c|c|c|c|}
\hline $\begin{array}{l}\text { Failure Mode } \\
\text { Degradation Type }\end{array}$ & or & $\begin{array}{l}\text { Mechanism or } \\
\text { Precursor }\end{array}$ & Metrology Method(s) \\
\hline \multirow[t]{7}{*}{ LID } & & 0 & Band-edge $(\mathrm{BE})$ photoluminescence \\
\hline & & & Deep-level PL [46] \\
\hline & & & FTIR [47] \\
\hline & & & Inert gas analysis [44] \\
\hline & & & Auger electron spectroscopy (AES) \\
\hline & & $\mathrm{Fe}$ & LIBS [48], FeB-pair splitting, GDMS [47] \\
\hline & & B & $\begin{array}{l}\text { Secondary ion mass spectrometry (SIMS), } \\
\text { Electron energy-loss spectroscopy (EELS) [49], } \\
\text { LIBS [48] }\end{array}$ \\
\hline \multirow[t]{5}{*}{ OSF rings } & & O precipitation & Band-edge (BE) photoluminescence (PL) \\
\hline & & & Deep-level PL [46] \\
\hline & & & FTIR [47] \\
\hline & & & Inert gas analysis [44] \\
\hline & & & Auger electron spectroscopy (AES) \\
\hline \multirow[t]{21}{*}{ Shunts } & & Cu contamination & $\begin{array}{l}\text { photoluminescence (PL), Deep-level PL [50], } \\
\text { Laser-induced breakdown spectroscopy (LIBS) }\end{array}$ \\
\hline & & & $\begin{array}{l}\text { [48], Glow discharge mass spectrometry } \\
\text { (GDMS) [47] }\end{array}$ \\
\hline & & C & FTIR [51] \\
\hline & & & Inert gas analysis [44] \\
\hline & & & Auger electron spectroscopy (AES) \\
\hline & & $\mathrm{Fe}$ & LIBS [48] \\
\hline & & & FeB-pair splitting \\
\hline & & & GDMS [47] \\
\hline & & & XPS/Auger, x-ray XPS [52] \\
\hline & & $\mathrm{Ca}$ & LIBS [48] \\
\hline & & & XPS/Auger, x-ray XPS [52] \\
\hline & & $\mathrm{N}$ & FTIR [47] \\
\hline & & & Inert gas analysis [44] \\
\hline & & & Auger electron spectroscopy (AES) \\
\hline & & Al & GDMS [47] \\
\hline & & $\mathrm{Ti}$ & GDMS [47] \\
\hline & & $\mathrm{Cr}$ & GDMS [47] \\
\hline & & High Z- impurities & Neutron activation analysis (NAA) [44] \\
\hline & & Metals on the surface & $\begin{array}{l}\text { Inductively couples plasma mass spectroscopy } \\
\text { (ICP-MS) SEMI MF1724 [44] }\end{array}$ \\
\hline & & & X-ray fluorescence spectroscopy (XRF) \\
\hline & & $\begin{array}{l}\text { The electrical activity of } \\
\text { traps }\end{array}$ & $\begin{array}{l}\text { Deep-level transient spectroscopy (DLTS), } \\
\text { Electron spin resonance (ESR) [53] }\end{array}$ \\
\hline
\end{tabular}




\subsubsection{Gap Analysis}

Sampling strategy. The sampling strategy for feedstock analysis is important and must be carefully developed. Many elemental analysis techniques are expensive and/or take a significant amount of time. As a result, not every chunk, granule, or fines can be tested. A fast and accurate method, such as laserinduced breakdown spectroscopy (LIBS) could be useful [48].

FBR shortcomings. In order to overcome FBR shortcomings highlighted in the reliability challenges section, new reactor design including internal wall coating and alternative internal heating via microwave or favoring exothermic reactions have been suggested [41]. Perhaps metrology can play a role in assessing the condition of the internal wall coating, regulating temperature, and in monitoring insitu particle size and distribution.

\section{Ingot Production}

During crystal growth, the impurity profile and material quality are significantly affected. New impurities are introduced, and existing impurities are redistributed. Thermal effects, impurities, and other factors (e.g. rotation speed, heat zone design, etc.) will affect the crystal quality and result in stress, point defect, twins, dislocation, grain, etc. Impurities and grain boundaries can combine to create defect clusters that can also have a detrimental effect. It is important to note also that the effects of impurities and defects are convoluted with other production areas (e.g. feedstock production, cell production, etc.). In this section, there is an attempt to decouple or isolate the ingot/brick production from other production areas. Ultimately, the noticeable degradation in performance and/or failure of solar cells and modules is the result of the aggregated effect of the changing impurities and defects profile throughout the entire manufacturing process.

In general, the grand challenges for ingot production over the past few years have been to optimize the hot-zone design to lower power consumption and increase ingot pulling speed; improve crucible and crucible coating quality to reduce impurities; control the uniformity of the dopant elements, especially phosphorus for n-type substrates; and recycle recovered Si effectively (both cropped pieces and kerf fines).

\subsection{Crystal Growth Processes}

Crystal growth may be split into the following classifications: monocrystalline, multicrystalline, and quasi-monocrystalline. The following sections detail manufacturing techniques for each of these crystal growth classifications.

\subsubsection{Monocrystalline Processes}

\subsubsection{Czochralski Process (CZ)}

\subsection{Traditional CZ Growth}

Traditional CZ growth involves the following steps: (1) filling up a crucible made of amorphous silica produced from an arc-fusion process using quartz with high purity polysilicon and calculated amounts of B or P dopant, (2) melting the Si in the crucible, (3) dipping a crystallographically oriented single crystal seed (typically $<100>$ ) into the melt, (4) withdrawing the seed crystal while rotating both the seed crystal 
and the crucible in order to create and stabilize a cooler zone at the center of the surface of the melt by adding rotational driven convection to the thermal convection, (5) pulling fast at first to ensure a dislocation free crystal (this "dash" process reduces ingot diameter to a few millimeters), (6) decreasing the growth rate to increase the ingot diameter, and (7) significantly increasing growth rate to establish a cylindrically shaped crystal when near the required diameter. At the same time, the melt temperature is reduced to optimize growth rate for diameter control and productivity.

\subsection{Continuous CZ Growth}

The anticipated push towards n-type (higher lifetime) substrates in the PV industry has led to an increased interest in continuous CZ. Although often casually referred to as continuous $C Z$ in the literature, it is in reality a continuous recharge CZ. A continuous supply of fresh polysilicon and dopant during growth results in long-body crystals and uniform resistivity, which is difficult, if not impossible, to achieve in traditional batch $\mathrm{CZ}$ growth. The ingot length is in principle determined by length of pull chamber instead of the crucible, hot zone, and puller tank size. As a result, productivity is increased. In practice, the ingot length is dependent on length of pull chamber plus volume of crucible, size of the hot zone and accumulation of impurities in the ingot. Disadvantages are increased process complexity, much longer run time, and a need for good purity feedstock. Furthermore, continuous CZ growth is also limited by the life of the quartz crucible and accumulation of dopants in the melt due to segregation coefficients. Crucible life may be 3 to 4 pulls, but 2 pulls per crucible is the current practical limit.

\subsection{Magnetic CZ Growth}

Magnetic CZ growth is similar to the traditional batch CZ growth; however, the growth is performed in the presence of a magnetic field. The magnetic field is applied to the melt for the purpose of disrupting convection currents that otherwise cause non-uniform incorporation of dopant impurities as well as oxygen and carbon in the growing crystal. It has been observed that, depending on the direction and magnitude of both the crystal and crucible rotational speed, the concentration of oxygen can be significantly reduced [54]. This is because the magnetic field reduces the surface contact of the melt with the walls of the crucible, so less oxygen is incorporated into the melt due to reduced dissolution of the quartz. There are several possible configurations for the time-dependent magnetic fields: a transverse magnetic field (TMF), a rotating magnetic field (RMF), or heater magnets, whether internal or external.

\subsubsection{Float Zone Process (FZ)}

The FZ process produces crystals with higher purity than the $\mathrm{CZ}$ process. One advantage of $\mathrm{FZ}$ is the potential of a near oxygen free crystal due to it being a crucible-free crystal growth process. FZ ingots can be purified from carbon and phosphorus by making several zone passes and concentrating impurities in the tail of the ingot. However, when using the FZ process, it is not easy to grow crystals with large diameters (i.e. $>150 \mathrm{~mm}$ ). 


\subsubsection{Multicrystalline Processes}

\subsubsection{Casting}

In casting, the melted raw material is transferred from its original crucible to another crucible for solidification. The crystallographic defects due to impurity precipitates have been studied by SEM, EDX, EBSD and EBIC [55]. Furthermore, scanning infrared polariscope (SIRP) has been used for characterization of residual strain distribution in casting ingot [56].

\subsubsection{Bridgman technique}

In the Bridgman method, one of the most well-established methods for crystalline Si ingot production, raw material is melted in a crucible followed by a cool down process to allow for crystalline growth. Different approaches for the cool down processes have been developed and practiced. In this section the pros and cons of each approach will be discussed.

\subsection{Directional Solidification (DS)}

The Bridgman DS method is primarily used for the production of multi-Si solar cells. In this technique, since the melt and crystals are in direct contact with the crucible, multi-grain growth becomes inevitable. Although the multi-grain phenomenon may be reduced by using a silicon nitride liner, these liners can also cause crystal contamination. Whenever a transition from single crystalline to multicrystalline is considered, the presence of grain boundaries (GB) and their nature is the main concern that needs to be addressed. It has been shown that large grained and columnar multi-Si, prepared via DS, is an acceptable, low cost alternative to CZ silicon, as long as the GB orientation is parallel to the carriers' diffusion path to the junction and the base contact [57].

The main drawback of the DS process is the use of a quartz crucible, which not only limits the size of the ingots, but also releases impurities such as silicon nitride. Furthermore, accumulation of a high level of impurities at the solid-liquid interface may inhibit DS growth and instead cause dendritic growth. Electron Beam Induced Current (EBIC) is one of the metrology techniques that has been used for contrast mapping of $\mathrm{O}, \mathrm{C}$, and $\mathrm{N}$ impurities in the GBs. Segregation of carbon and oxygen at the GB can be detected by FTIR and SIMS. Iron is one of the most common and harmful impurities in p-type mc-Si. In order to show iron distribution in mc-Si ingots grown by DS, Kvande et al. [58] have used multiple characterization techniques such as neutron activation analysis (NAA) and glow discharge mass spectrometry (GDMS). Synchrotron X-ray radiography (SXR) and synchrotron white beam X-ray topography (SWBXT) have shown to be effective in-situ imaging techniques to observe the real time dynamic evolution of the solid/liquid interface, its morphology, the interface velocity, grain orientation, and twinning or stresses throughout the solidification process [59].

\subsection{Electromagnetic Casting (EMC)}

Multi-Si manufacturing via EMC uses a cold crucible induction melting where an electromagnetic field is applied to melt metals without any contact to the crucible. This technique has been used in commercial production of ingots with nearly 1 ton weight in batch mode but continuous casting efforts have not shown much progress [60]. 


\subsubsection{Gradient freeze technique (Quasi-monocrystalline Si)}

This seed-assisted Bridgman technique produces single crystalline material that has advantages of both $\mathrm{CZ}$ and $\mathrm{mc}-\mathrm{Si}$, i.e. square, single crystal, low structural defect density, and low cost. This technique produces material with higher minority carrier lifetime and uniform lifetime compared to mc-Si [61]. While this material has shown a lot of promise, there are still major issues with defect clusters through significant parts of the brick $[62,63]$.

\subsubsection{Optimization of ingot production}

\subsubsection{CZ Growth Optimization}

Various challenges associated with $\mathrm{CZ}$ growth are listed below:

High oxygen $(O)$ content. P-type CZ-mono wafers have high electronic quality, although they are known to suffer from light-induced degradation (LID) because of the oxygen content. The source responsible for oxygen in $\mathrm{CZ}$ silicon is quartz $\left(\mathrm{SiO}_{2}\right)$ crucible dissolution [64]. Most (> 98\%) of the dissolved oxygen evaporates as $\mathrm{SiO}$; the remainder is incorporated into the silicon crystal. In order to reduce the Ocontent, strategies involve (1) using an alternative crucible material, (2) using a steady magnetic field, and (3) switching to a FZ process.

High C-content. The main sources of carbon are the graphite parts. An abnormal concentration is indicative of various and identifiable contamination paths [64].

Expensive equipment and process cost. In order to reduce costs, improvements in the hot zone's design (lower argon and power consumption, increase pulling rate) and the crucible (lower cost and longer lifetime) are needed. A 35\% increase in the pulling rate was proposed through the optimization of the argon flow guide, the geometries of the radiation shield, and the side/bottom insulations [65]. By optimizing the original argon flow path, the heater and graphite susceptor lifetimes can be significantly lengthened. Changing the argon flow path prevents the graphite heater and SiO from reacting with graphite and forming silicon carbide, which deteriorates the heater and shortens heater's lifetime.

Process yield. Improvement of the yield can be achieved through charge increase. Increasing the charge can be done by using a larger crucible or using continuous charging. Since traditional crystal pulling is a batch process, the chamber for holding the crystal has a limited length. An approach is to have multiple charges, that is, after a crystal is pulled out and removed, without cooling down, the new material can be fed from the feeder. Continuous charging such as in continuous CZ is another option. Furthermore, particles are responsible for the formation of dislocations, which are detrimental to the yield. Therefore, particles due to crucible erosion and $\mathrm{SiO}_{\mathrm{x}}$ deposits need to be prevented. Coating the crucible walls with a very small amounts of a barium compounds such as $\mathrm{Ba}(\mathrm{OH})_{2}, \mathrm{BaCO}_{3}, \mathrm{BaO}$ or $\mathrm{Ba}$ in solution in the $\mathrm{Si}$ melt causes the surface of the crucible to uniformly denitrify at crystal growth temperatures. The near perfectly smooth devitrified wall surface is considerably less likely to generate melt-borne particles when the dissolution of the crucible wall exposes bubbles and refractory oxide impurities.

Doping non-uniformity for n-type. The uniformity of the dopant can be improved though recharging strategies such as continuous CZ. Continuous CZ allows for metered dopant/poly introduction during crystal growth for "uniform" axial resistivity for both $p$-type and n-type ingots. 
Strong turbulent melt power. The control of convective flow can be done using time-dependent magnetic fields: TMF, RMF, and heater magnets.

\subsubsection{DS growth Optimization}

Typical approaches to solve the various challenges associated with DS growth are:

Direct contact of crucible wall. Reduced contamination from the crucible wall may be achieved by improving the crucible coating or using an alternative crucible material.

Formation of $\mathrm{Si}_{3} \mathrm{~N}_{4}$ and $\mathrm{SiC}$ precipitates. The strategy is to reduce contamination with $\mathrm{N}$ and $\mathrm{C}$ as well as improve the convective transport of $\mathrm{N}$ and $\mathrm{C}$ in the $\mathrm{Si}$ melt. This can be achieved by using better quality feedstock, careful handling of materials, and improving the stirring of the melt.

High contents of metal impurity. The approach here is to reduce the metal content, especially inside grain boundaries. Better purification of feedstock can help. Ultimately, advanced gettering strategies have to be identified.

High density of grain boundaries and related defects. A simple solution is to grow larger grains. This can be achieved by using a seed crystal and optimizing the growth process to minimize multi-grain growth and dislocations.

\subsection{Reliability Challenges}

\subsubsection{Light Induced Degradation}

Light induced degradation refers to the degradation of performance that occurs when a module is first exposed to sunlight as a result of carrier injection [66]. LID is attributed to boron (interstitial $B_{i}$ and not substitutional $\left.\mathrm{B}_{s}[67,68]\right)$, oxygen $\left(\mathrm{O}_{2 i}\right)$ and $\mathrm{Fe}$. With respect to these impurities, there are two main lifetime reducing defects. One is the formation of boron-oxygen (B-O) complexes, mostly $\mathrm{B}_{i}-\mathrm{O}_{2 i}[69]$. The other is the interstitial iron formed when iron-boron pair (Fe-B) dissolves upon exposure to light [70]. Two important facts about LID are: (1) LID scales with the net doping and not the total B concentration and (2) the Fe-B defect is injection dependent whereas B-O complexes are not. Recently, even a low concentration of interstitial $\mathrm{Cu}$, which has high solubility and diffusivity in silicon at room temperature, was observed to result in LID as well [71, 72].

LID greatly influences $B$ doped $C Z$ silicon growth (1-5\% degradation) [70, 71, 73]. LID does not affect $B$ doped $\mathrm{FZ}$ silicon wafers as much because of their low $\mathrm{O}$ content. Also, the effect of the B-O pair is not as critical in multi-Si cells (0.5-3\% degradation) [70, 74-77]. Block casting results in typically higher concentration of impurities (metallic and others), grain boundaries, twins, dislocations, whos combined impact on lifetime degradation is greater in comparison to B-O pairs alone under sunlight [74, 78]. On the other hand, upgraded metallurgical-grade based multi-Si (UMG multi-Si) cells seem to be significantly affected by LID, especially at elevated temperature [70, 74-77] (0.5-10\% degradation). Similarly, upgraded metallurgical-grade based mono-Si (UMG mono-Si), whether p-type (B-doped) or ntype (P-doped), suffers from LID [79] due to compensation from the $B$ inherently found in high concentration in UMG Si in the latter case. UMG mc-Si is also affected at elevated temperature in the dark resulting in temperature induced degradation (TID). For instance, it was observed that UMG mc-Si 
cell stored in the dark for 450 hours at $85^{\circ} \mathrm{C}$ resulted in almost $6 \%$ power loss, and only half of this could be recovered in an annealing step [66].

LID is affected during various steps in the manufacturing process. The main processes that play an important role in LID are [70]:

- Feedstock quality (impurity concentration)

- Base resistivity and net doping

- Silicon crystallization (defect and doping distribution)

- Wafering and cleaning (surface contamination)

- Cell process (defect diffusion, gettering effects)

- Cell architecture [80]

- Passivation [81]

In order to mitigate LID, many approaches have been considered in the literature. Proposed strategies during ingot/brick production include:

- $\quad$ Avoiding the use of 1-2 $\Omega$-cm B-doped CZ silicon (use high resistivity) [71, 82]

- Substituting B with Ga [82-84] although Cu and Ga resulted in LID [85]

- Substituting B with In was proposed [86]. Recently, In-doped Si was shown to exhibit LID as well [87]

- Reducing $O$ content (e.g. by damping melt flows with magnetic fields) [82, 83]. However, an increase in cost and energy consumption is expected [86].

- Using n-type P-doped CZ silicon not produced from UMG [73, 79, 82, 83, 88, 89]

- Using quasi-monocrystalline silicon technology which has reduced $O$ content. Also, dislocation rich $\mathrm{Si}$, as in the case of quasi-monocrystalline silicon, results in an higher activation energy of BO complexes [90].

Proposed strategies during cell fabrication include:

- Process optimization (tube furnace, belt furnace, rapid thermal annealing) [82]

- Using a SiCxNy antireflection (AR) coating. Carbon diffuses into silicon during contact firing and forms $\mathrm{C}-\mathrm{O}$ dimers $\left(\mathrm{CO}_{2 i}\right)$ instead of $\mathrm{B}-\mathrm{O}_{2 i}$ complexes [91].

- Using $\mathrm{Al}_{2} \mathrm{O}_{3}$ as a passivation layer [92]

Proposed strategies for post module fabrication consist of:

- Annealing at temperature above $200{ }^{\circ} \mathrm{C}$ for more than 30 minutes [81]

- Illuminating or applying a forward voltage to a device at an elevated temperature (100-200 $\mathrm{kWh} / \mathrm{m}^{2}$ at $60{ }^{\circ} \mathrm{C}$ [66] while [93] recommends temperatures above $90^{\circ} \mathrm{C}$ )

- Depositing a large negative charge onto the wafer surface [71] 
Recent progress seems to indicate that LID can be separated into two components: surface and bulk LID. Although bulk LID can be fully recovered upon annealing, surface LID cannot. This is ascribed to the degradation of the SiN:H-Si interface and has been observed in low-Fe mono-Si and multi-Si cells alike [81]. In addition, Float-zone (Fz) samples as well as a-Si:H/c-Si (100) and a-Si:H/c-Si (111) interfaces have also been observed to deteriorate under light exposure while the $\mathrm{Al}_{2} \mathrm{O}_{3} / \mathrm{c}-\mathrm{Si}(100)$ interface showed light-induced "improvement" [92]. This obviously would have important implications on passivation schemes as wafers/cells get thinner and surface recombination becomes even more critical.

\subsubsection{Shunts}

Shunts are localized short circuits in the PN-junction area or at the edge resulting in reverse currents, junction breakdown, and hot spots. Shunts can be divided into three types with respect to their origin:material-induced, process-induced, and field-induced shunts.

Sources of material-induced shunts are:

- Metal-decorated small-angle grain boundaries

- $\mathrm{Si}_{3} \mathrm{~N}_{4}$ inclusions

- $\mathrm{SiC}$ precipitates

Sources of process-induced shunts are:

- Residues of the emitter at the edge of the cells

- Cracks (from high residual stress due to silicon solidification or other)

- Recombination sites at the cell edge

- Schottky-type shunts below grid lines

- Scratches

- Aluminum particles at the surface

Sources of field-induced shunts are:

- Large negative bias voltage

By far, most of the shunts are process-induced. However, we will focus only on material-induced and field-induced shunts in this section since it relates directly to crystal growth. First, metal-decorated small-angle grain boundaries are the result of crystal defects being decorated by impurities, and thus can be strong recombination sites leading to non-linear shunts similar in nature to edge shunts and scratches [94].

$\mathrm{Si}_{3} \mathrm{~N}_{4}$ inclusions also result in shunts that have a nonlinear I-V characteristic (diode-like) [94]. Recently, it was observed that there were two types of $\mathrm{Si}_{3} \mathrm{~N}_{4}$ inclusions resulting in shunts, monocrystalline $\mathrm{Si}_{3} \mathrm{~N}_{4}$ fibers (less than $1 \mu \mathrm{m}$ in diameter and several mm long) and hexagonally shaped $\mathrm{Si}_{3} \mathrm{~N}_{4}$ crystallites (few tens of $\mu \mathrm{m}$ in diameter and several hundreds of $\mu \mathrm{m}$ long). Si3N4 coating on the surface of the crucible, which is used to reduce the residual stress in silicon, is the source for these inclusions. Furthermore, the residual stress in silicon resulting from the growth process is believed to play a role in the formation of $\mathrm{SiC}$ precipitates [95]. 
Lastly, SiC precipitates can likewise lead to strong ohmic shunts and are viewed as the most dangerous material-induced shunts [94]. These are due to C contamination from the graphite heaters in the crystallization furnace. SiC filaments are on the order of 1-3 $\mu \mathrm{m}$ in diameter. An SEM investigation shows that it is not the SiC precipitates themselves that represent the conducting channels but ring-shaped inversion channels around them [95]. The presence of SiC precipitates does not depend on the grain boundary type. Mechanical stress may play a role in the formation of $\mathrm{SiC}$ precipitates. Since the $\mathrm{SiC}$ grain boundary precipitates follow the interface morphology, they are obviously growing during or shortly after the crystallization process. Concerning crystal structures, block-casted multi-Si is strongly affected, especially wafers obtained from the top of the blocks/bricks. It was observed that SiC precipitates tend to migrate to the top of silicon blocks during casting. Good quality block-cast silicon solar cells can help mitigate this type of precipitate [95]. Field-induced shunts may appear under a large reverse bias of -5 to $-20 \mathrm{~V}$, especially in multi-Si cells.

\subsubsection{Crystallographic Defects}

Typical crystallographic defects are:

- Point defects - self-interstitials, vacancies, interstitial impurities such as oxygen, substitutional impurities such as dopants and carbon,

- Line defects - edge and screw dislocations, dislocation loops are created under the high stress conditions during thermal cooling, for example

- $\quad$ Planar defects - stacking faults come from the concentration of silicon self-interstitials, preferentially around nucleation sites (e.g. oxide precipitates, metal precipitates or mechanically damaged locations in the lattice)

- Bulk defects - Voids, oxide precipitates, swirls, interstitial and vacancy clusters, large dislocation loops

\subsubsection{Cracks}

- The thermal residual stress during casting can result in breakage of wafers and cells before, during, and after both solar cell and module manufacturing

- While elements such as $\mathrm{O}, \mathrm{C}$, or $\mathrm{N}$ can increase strength, it has been shown that precipitates made of these elements tend to create localized areas with significantly higher local stress and result in breakage

- Ingot and brick shaping can also result in crack initiation, which then can cause the wafers and cells to break. Equally critical are the edge roughness; polishing or etching of the silicon ingot prior to wafering process can increase the strength of the wafers by $33 \%[96,97]$

\subsection{Metrology Strategies}

\subsubsection{Existing Metrology Techniques}

Typical ingot parameters measured in-line prior to wafering consists of:

- Geometry (3D) e.g. Side lengths, phase lengths, diagonal lengths, angle, and flatness of the side

- Chamfers (3D)

- Detection of chipping, rills and other defects (3D) 
- Surface roughness (3D), reflection

- Cracks, SiN/SiC inclusions

- $P N /$ junction

- Lifetime

- Resistivity

Available techniques to measure these above mentioned parameters are:

- 3D inspection system. Inspection systems typically consist of halogen light within fiber glass and a camera.

- High resolution IR camera

- Photoluminescence

- Quasi steady state photoconductivity (QSSPC) or microwave detected photoconductive decay ( $\mu$-PCD)

- Laser optical line scanners (3D)

\subsubsection{Metrology Techniques Beneficial for Reliability}

Table 8 summarizes the techniques useful in predicting failure modes.

Table 8. Metrology techniques useful in predicting failure modes or performance degradation during crystal growth

\begin{tabular}{|c|c|c|}
\hline $\begin{array}{l}\text { Failure Mode or } \\
\text { Degradation Type }\end{array}$ & $\begin{array}{l}\text { Mechanism or } \\
\text { Precursor }\end{array}$ & Metrology Method(s) \\
\hline LID & Base Resistivity & $\begin{array}{l}\text { GDMS/4-point probe [98] } \\
\text { GDMS/ } \mu \text {-PCD [98] } \\
\text { GDMS/Hall measurement [98] }\end{array}$ \\
\hline LID & $\begin{array}{l}\text { Impurity } \\
\text { segregation }\end{array}$ & $\begin{array}{l}\text { Fourier transform infrared (FTIR) [99] } \\
\text { Glow-discharge mass spectrometry (GDMS) [99] } \\
\text { Laser-induced breakdown spectroscopy (LIBS) [48] } \\
\text { Transmission electron microscopy (TEM) [98] } \\
\text { Energy-dispersive spectroscopy (EDS) [98] } \\
\text { Photoconductance (PC) [100] }\end{array}$ \\
\hline Shunts & $\begin{array}{l}\text { Impurity } \\
\text { segregation }\end{array}$ & $\begin{array}{l}\text { Fourier transform infrared (FTIR) [99] } \\
\text { Glow-discharge mass spectrometry (GDMS) [99] } \\
\text { Laser-induced breakdown spectroscopy (LIBS) [48] } \\
\text { Transmission electron microscopy (TEM) [98] } \\
\text { Energy-dispersive spectroscopy (EDS) [98] } \\
\text { Photoconductance (PC) [100] }\end{array}$ \\
\hline Shunts & $\begin{array}{l}\text { Crystallographic } \\
\text { defects }\end{array}$ & $\begin{array}{l}\text { IR Transmission [99] } \\
\text { PL Tomography [101] } \\
\text { Electron backscattered diffraction (EBSD) [98] } \\
\text { Photoconductance (PC) [100] }\end{array}$ \\
\hline Cracks & Residual stress & Near infrared (NIR) linear birefringence [102] \\
\hline Cracks & Edge roughness & Laser optical line scanners (3D) \\
\hline Cracks & Imaging & $\begin{array}{l}\text { IR Transmission } \\
\text { Scanning Acoustic Microscope (SAM) }\end{array}$ \\
\hline
\end{tabular}




\begin{tabular}{ll}
\hline Cracks & Lifetime \\
& RF-QSSPC [103] \\
& RF-PCD \\
& Infrared lifetime mapping \\
& Carrier density mapping [104] \\
& $\mu-P C D[103]$ \\
& PL [103, 105-107] \\
& PL Tomography [101] \\
& MD-PCD \\
\hline
\end{tabular}

\subsubsection{Gap Analysis}

Metrology techniques for ingots/bricks potentially of interest that are not readily available are:

- 3D dislocation mapping. IR imaging can detect cracks and inclusions. PL can measure dislocations in a qualitative way. There still remains a need to develop a fast quantitative technique to measure dislocations in ingots. Infrared polariscopy is a viable candidate [ref].

- Residual stress imaging. Although Near Infrared (NIR) linear birefringence was demonstrated as a potential approach to map out residual stress within an ingot, this takes time. There is a need for a quick imaging solution for in-line metrology

- $\quad$ Visual inspection. Unlike CZ growth, the growth process in casting and DS methods cannot be observed in-situ through a port/window or a camera.

\section{Wafer Production}

Wafer production has also seen its fair share of challenges over the past few years. The main ones consist of the following:

- Reduction of kerf loss and kerf fine recycling

- Lowering cost (both traditional and kerfless approaches)

- Thin wafers handling and processing (e.g., limiting breakage)

- Unified incoming wafer specifications and standards

- Grain boundary passivation of multi-Si wafers

- Determination of electrical activity of crystallographic defects in a wafer

- Understanding critical crack lengths vs. wafer thickness

- Wafer consistency, especially in the case of multi-Si and quasi-monocrystalline wafers

\subsection{Processes}

Wafering, the process whereby the silicon wafer is formed from the ingot, is typically accomplished by traditional (sawing) techniques, or non-traditional (kerf-less) techniques. In the traditional technique, a mechanical saw is employed to cut the ingot, generating silicon dust (the "kerf") from the location of the cut. In kerf-less technologies, the approach utilizes techniques that do not experience silicon waste. The following sections describe these two main classifications of wafering technologies. 


\subsubsection{Traditional Wafering}

\subsubsection{Slurry Wire Saw}

Slurry-based multi-wire sawing is currently the main technique used to slice silicon ingots and bricks into wafers. Cutting is achieved by a combination of moving steel wires and a slurry consisting of abrasive particles (e.g. SiC) and a carrier fluid (e.g. polyethylene glycol). The slurry is brought to the steel wires through high flow-rate nozzles. Key factors are the wire speed, table speed, the solid fraction of SiC in the slurry, the slurry viscosity, and the size distribution and shape of the SiC particles.

Typically, silicon carbide ( $\mathrm{SiC}$ ) particles are used as abrasives. The volume fraction of solid SiC particles can vary between 20 and $60 \%$ and their mean grain size between 5 and $30 \mu \mathrm{m}$. The various abrasive size designations can be found elsewhere [108]. Polyethylene glycol (PEG) is normally used as the carrier fluid. Oil-based slurries have several disadvantages such as wafer singulation, cleaning, and disposal.

Surface damage shows maximum crack depths in the range of 10 to $20 \mu \mathrm{m}$. It was also observed that surface roughness and crack depth decreases from wire-inlet to the wire-outlet [109]. In addition, a lower abrasive concentration results in a thinner distribution of the fracture force and reduced roughness of the resultant wafers [110].

Recent progress in slurry wire sawing is the use of structured wires, which have the advantage of higher cutting speed and wire durability, thus reducing the cost, while at the same time not increasing the wafer surface damage [111].

\subsubsection{Diamond Wire Saw}

Unlike slurry-based sawing, which relies on loose SiC particles within a slurry as abrasives, diamond wire sawing relies on diamond particles metal plated onto a steel wire as fixed abrasives. There are important differences between slurry-based and diamond wire sawing methods:

- Surfaces of slurry-cut wafers tend to have more pits, while diamond wire-cut wafers exhibit scratches and microcracks. This happens especially when sharp diamond grits are used, resulting in a fracture rather than a ductile mode of cutting [112]. Additionally, there is a noticeable phase change [113] and increase in stress (both tensile and compressive - stress state varies across the surface of the wafer so both are present simultaneously but in different locations) on the wafer surface [114].

- The mechanical strength of wafers $[115,116]$ strongly depends on the surface morphology. Because cracks are produced along the wire direction in diamond wire-cut wafers, the failure strength of wafers along the wire direction is reduced compared to slurry-cut wafers, while it is increased in the direction perpendicular to the wire [113,117].

- Additional benefits consist of a higher throughput, improved total thickness variation (TTV) [113], reduced Si surface contamination, and reduced cost [118, 119]. All of these are becoming more critical as the wafer thickness continues to decrease in industry.

- Saw damage removal etch and texturing remains to be optimized because of the complex surface properties and the presence of amorphous silicon [120]. 
Based on the many advantages described above, it is anticipated that diamond wire sawing will replace slurry based sawing in a near future with a market share $>50 \%$ by 2020 according to the 2014 edition of the ITRPV.

\subsubsection{Non-Traditional (Kerfless) Wafering}

The surge in "kerfless" wafering methods in recent years sprung from an urgent need to reduce material cost/waste in the industry. Until recently, raw Si consisted of over $40 \%$ of the module cost, and stunningly, more than $50 \%$ of grown silicon ingots are wasted or recycled because of cropping, squaring, and wire sawing. While over 18 kerf-free wafering methods have been identified in another report [121], we here focus on the three main categories: solid phase, liquid phase, and gaseous phase processes.

\subsubsection{Solid Phase Wafering}

Solid phase wafering methods have the advantage of not requiring any changes in upstream silicon processing steps. Because these "cleave-layer based" wafering methods often require a specific crystallographic plane, mono-Si is the preferred substrate. Typical durability challenges with solid phase wafering are breakage, shunts, and stress due to the surface and sub-surface damage and micro-crack formation.

\subsection{Implant-Cleave Processes}

The implant-cleave technique is a two-step process as its name indicates. During the first step, a high energy hydrogen (proton) beam irradiates a thick silicon substrate. Because the protons all have the same energy, after propagating a certain distance proportional to their energy they come to a stop at the same depth and thus form a stressed cleave layer. The second step consist of an annealing step that results in cracks propagating along the stressed cleave layer as hydrogen is released from the substrate [121].

The energy of the proton beam determines the silicon wafer thickness. Implant energies of 1-4 MeV are typically used to produce wafers with thicknesses ranging from $20 \mu \mathrm{m}$ to $150 \mu \mathrm{m}[121,122]$. The depth of the surface damage is estimated to be about $10 \%$ of the target cleave layer depth, which is $20 \mu \mathrm{m}$ for a $200 \mu \mathrm{m}$ thick wafer, or $10 \mu \mathrm{m}$ for a $100 \mu \mathrm{m}$ thick wafer and so forth [122].

\subsection{Exfoliation Processes}

The exfoliation process relies on depositing a material with a different coefficient of thermal expansion (usually a metal or polymer) onto a thick silicon wafer. Depending on the deposition process, accumulation of hydrogen at the interface could also occur, which can help with the exfoliation process [123]. Subsequently, an annealing process takes place resulting in significant internal stresses at the interface and thus in the exfoliation of a foil substrate. Exfoliation processes are used at AstroWatt, IMEC (SLiM-Cut) [124, 125], and IBM [126]. A metal-based approach (e.g. nickel, nickel/chromium, silver/aluminum, etc . [127]) involves high temperatures resulting in silicon being ductile and, thus, poor foil quality due to plastic deformation. High temperatures can also increase contamination. A polymerbased approach (e.g. epoxy [127]) is advantageous due to the lower annealing temperatures, which are 
well-within the brittle regime of silicon [53]. Recently, a single side heterojunction cell has been demonstrated using a $25 \mu \mathrm{m}$ exfoliated c-Si foil with an efficiency of $12.5 \%$ [123] and $14.8 \%$.

\subsection{Laser Processes}

Laser wafering [128] consists of focusing a laser at a particular depth in a silicon ingot, where a defect or pit is created on the order of the spot size. By rastering the beam across the entire subsurface of the ingot, a cleave layer is formed. An anisotropic etch or anneal steps can be used for cleaving individual wafers. Unlike ion implantation, more than one wafer can be created at one time as the laser can be focused at various depths with no damage to the silicon itself other than at the desired depth. Furthermore, a minimum thickness of $10 \mu \mathrm{m}$ can be achieved while there is not any upper bound.

Another interesting laser process for wafering combines the concepts of using thin liquid-jet as waveguide for a laser and wet chemical processing step [129]. Water and $\mathrm{KOH}$ have been used as liquid carriers to enhance cutting via etching as well as removing any surface damage within a single step. The depth of surface damage was estimated to be on the range of $11 \mu \mathrm{m}$.

\subsubsection{Liquid Phase Wafering}

The silicon liquid phase wafering processes are also referred to as direct wafer processes. The liquid phase approach to wafering has been the most widely implemented kerfless method at the industrial scale because of its potential for high growth rate (E.g. About $1 \mathrm{~mm}$ per minute for horizontal ribbon growth HRG [130]). Solar cells made from liquid phase wafering methods have demonstrated efficiencies in excess of 16\% [131]. Although many variations of liquid phase wafering have been considered, the most significant methods have proven to be silicon dendritic web growth (WEB), silicon edge-defined film-fed growth (EFG), string ribbon growth (SRG), and silicon ribbon growth on a substrate (RGS) [132]. The most recent variation is the direct wafer process from 1366 Technologies; efficiencies of $17 \%$ in customer trials have been reported using a standard cell line. Even though growing from the melt offers many advantages over standard wire sawing, mainly reduced material waste and cost, there are many disadvantages: high stress, high dislocation densities, multi-crystallinity, lowered contaminant segregation, all of which can present durability issues in terms of breakage and shunts.

\subsection{Dendritic Web Growth (WEB)}

Dendritic web growth relies on crystallographic and surface tension forces to form a web of silicon between dendrites during upward pulling. Typical characteristics are the formation of twins in central regions and thermal residual stress. Although twins are generally considered benign, residual thermal stress can result in the formation of crack and breakage. Because the material is mostly single crystal however, efficiencies above $17 \%$ have been reported for $4 \mathrm{~cm}^{2}$ cells [133].

\subsection{Edge Defined, Film Fed Growth (EFG)}

Edge defined, film fed growth allows for a ribbon or even octagon tubes of crystallized silicon to be formed while it is being pulled from the melt through a graphite die. Typical defects for EFG wafers have grain boundaries, dislocations, intersecting twins stacking faults and high concentration of impurities (carbon, oxygen, and metals). 


\subsection{String Ribbon Growth (SRG)}

Similarly, in the case of string ribbon growth, a silicon ribbon is formed between two carbon strings, which are pulled upward through holes in a flat crucible with molten silicon. Sovello AG has reported solar cells (untextured surface) fabricated using standard size string ribbon substrate with efficiencies of more than $16 \%$ [131].

\subsection{Ribbon Growth on Substrate (RGS)}

Ribbon growth on substrate is a high growth rate method that allows for the growth of a multi-Si wafer on a substrate which is pulled from the side of a casting frame full with molten silicon. Direct results of the fast growth are higher crystallographic defect densities (e.g. dislocations, grain boundaries) and impurities. Additionally, cell efficiencies tend to be lower than the other liquid phase wafering approaches, typically around $12 \%$ at best [134].

\subsubsection{Gas Phase Wafering}

\subsection{Epitaxial (Epi) Growth Processes}

Epitaxial growth processes require the use of appropriate substrates on which to grow a good quality epi layer (e.g. single crystal silicon wafer or other seed layers) as well as possibly a sacrificial layer (e.g. an oxide layer, ion implanted layer, or a porous silicon layer) [124]. Solar cell efficiencies up to $20.1 \%$ were recently obtained using a porous silicon sacrificial layer (SOLEXEL) and 19.2\% using an oxygen implanted layer (SIMOX method). Durability challenges may come from surface properties after separation and from the defect density in the epi-layer, which is related to the quality of the substrate. High defect density may play a role in breakage and shunts. Recently, it has been shown that porosity can be completely extracted from the epi-layer if high quality material and engineered macropores with large aspect ratios are used [135]. It turns out an epi-layer is not even needed since the carefully engineered macropores can be manipulated to exfoliate a high quality thin wafer from the thick substrate [136138].

\subsection{Reliability Challenges}

\subsubsection{Cracks and $\mu$-cracks}

Micro-cracking in wafers is inevitable, but micro-cracks do not have to induce catastrophic failure. Yet, micro-cracks and cracks can have an influence on the performance of solar cells [139, 140]. Typically micro-cracks ( $\mu$-cracks) will turn into cracks during cell/module manufacturing and beyond. In fact, cracks can grow in solar cells within a module due to mechanical loading and result in a degradation of performance [141-144]. On the other hand, cracks can result in catastrophic failure such as wafer or solar cell breakage, and others with potentially very serious consequences. In addition, localized hot spots due to micro-cracks can burn through silicon at over $1414^{\circ} \mathrm{C}\left(2,577^{\circ} \mathrm{F}\right)$ and result in significant damage such as front glass cracks, crack shadows, worm tracks, snail trails, front or back bubble delamination, dead cell sections, internal arcs at over $8000^{\circ} \mathrm{C}\left(14,000^{\circ} \mathrm{F}\right)$ and, even uncontained fires [145]. 


\subsubsection{Breakage}

There is a clear relationship between crack length and breakage [146]. Wafering is an important step in crack generation. The sawing process develops surface scratches and thickness non-uniformity which tend to lower wafer strength causing breakage [147]. SiC precipitates can cause sawing ditches and ridges to form on the surface of the wafer [148] and cause them to break during sawing. Residual stress, warping, when coupled to significant applied stress during cell/module manufacturing, can also result in breakage.

\subsubsection{Warping}

PV producers need their substrate to be flat from both a handling and material-printing process perspective. When non-flat substrates are handled in production, mechanical stress (e.g. screenprinting) can cause micro cracks to propagate to the point of failure during processing.

\subsubsection{Shunts}

Important shunting mechanisms:

- Cracks causing short circuit. Cracks created during wafering operations or subsequent fabrication steps can act as triggers to a tiny, intense hot spot during partial shading and reverse bias conditions.

- Material inclusions like $\mathrm{Si}_{3} \mathrm{~N}_{4}$ and SiC. Such material inclusions occur during crystal growth.

- Crystallographic defects. The mechanical force applied onto a wafer during sawing can results in dislocation, pinholes, etc.

\subsubsection{Stress}

Stress is an important precursor to cracks and breakage. A clear correlation between residual stress during wafering and fracture strength of crystalline silicon wafers has been established [114]. Subsequent fabrication steps can introduce more residual stress and further reduce the fracture strength of crystalline silicon wafers [149].

\subsubsection{Wire Failure}

The presence of SiC clusters on the surface of the wafer can result in catastrophic failure of the wire $[150,151] . \mathrm{Si}_{3} \mathrm{~N}_{4}$ inclusions typically serve as nuclei for $\mathrm{SiC}$ precipitates. If a wire fails during wafering, the entire ingot is typically lost.

\subsection{Metrology Strategies}

\subsubsection{Existing Metrology Techniques}

Standard parameters that are measured on incoming wafers prior to solar cell fabrication consist of:

- Thickness, TTV

- $\mu$-cracks, inclusions

- Saw marks, surface roughness

- Geometry

- Edge defects, chipping 
- Bow

- Lifetime

- Resistivity

- Grain size

- Strain

The metrology techniques typically used to measure these parameters are:

- Eddy current displacement sensors

- Optical and laser sensors

- Capacitive sensors

- Laser micrometer

- 2D/3D profile sensors (scanner)

- Imaging (IR and Visible)

- Quasi-steady-state photoconductance (QSSPC)

- Photoconductance decay ( $\mu \mathrm{PCD})$

- Photoluminescence (PL) [61]

- Surface photovoltage (SPV)

\subsubsection{Metrology Techniques Beneficial for Reliability}

This section highlights existing or novel metrology techniques that would be useful in predicting failure modes:

Potential induced degradation. PID related shunts are associated with stacking faults including Oxygeninduced Stacking Faults (OSF) [152]. OSF-rings originate from oxygen precipitates that act as nucleation sites for stacking faults typically in CZ silicon. Typical characterization of stacking faults relies on the Wright etch, which is highly toxic. An attractive in-line alternative would be photoluminescence although it has some limitations [153-155].

Cracks and $\mu$-cracks. Cracks are currently measured using IR imaging, which is quite effective. Attractive alternatives are photoluminescence (PL) and resonance ultrasonic vibrations (RUV), which is able to achieve measurement times close to 2 seconds per wafer to match the throughput of a typical production line. Although IR is limited by the diffraction limit, RUV is believed to be able to measure even smaller than $1 \mu \mathrm{m}$ [156]. Another exciting technique called 'edge-light' is quite sensitive and can be used with the ever versatile photoluminescence technique for crack detection. The advantage is the ability to detect much smaller cracks than possible with conventional equipment in multi-Si wafers [157].

Process induced shunts. Under reverse bias condition, early breakdown (Type 1 around $-4 \mathrm{~V}$ to $-5 \mathrm{~V}$ ) is most likely due to surface cracks. A crack detection strategy similar to the one described in the previous paragraph would be of interest. Defect-related breakdown (Type 2 around $-7 \mathrm{~V}$ to $-13 \mathrm{~V}$ ) is related to metal precipitates. A good impurity detection scheme and a clean wafering process are of interest. Two other valuable techniques are Laser-induced breakdown spectroscopy (LIBS) and photoluminescence $(\mathrm{PL})$. Avalanche breakdown (Type 3 around $-13 \mathrm{~V}$ to $-15 \mathrm{~V}$ ) is believed to be the result of deep-etch pits. 
Reducing sub-surface damage during wafering together with the ability to characterize the sub-surface damage is important.

Residual stress. Stress can lead to wafer breakage during cell or module fabrication. Recent publications have shown a clear correlation between residual stress and the measured fracture strength of wafers before and after the damage removal etch [114]. Infrared polariscopy is a fast and non-contact method for in-line measurement of stress.

Light induced degradation. Useful techniques on incoming wafers would be Fourier transform infrared (FTIR), photoluminescence (PL) [158, 159], surface photovoltage (SPV) [160], and PC/PL [161].

Table 9 summarizes useful wafer manufacturing metrology techniques for increased module reliability.

Table 9. Useful manufacturing metrology techniques during wafer production for increased module reliability

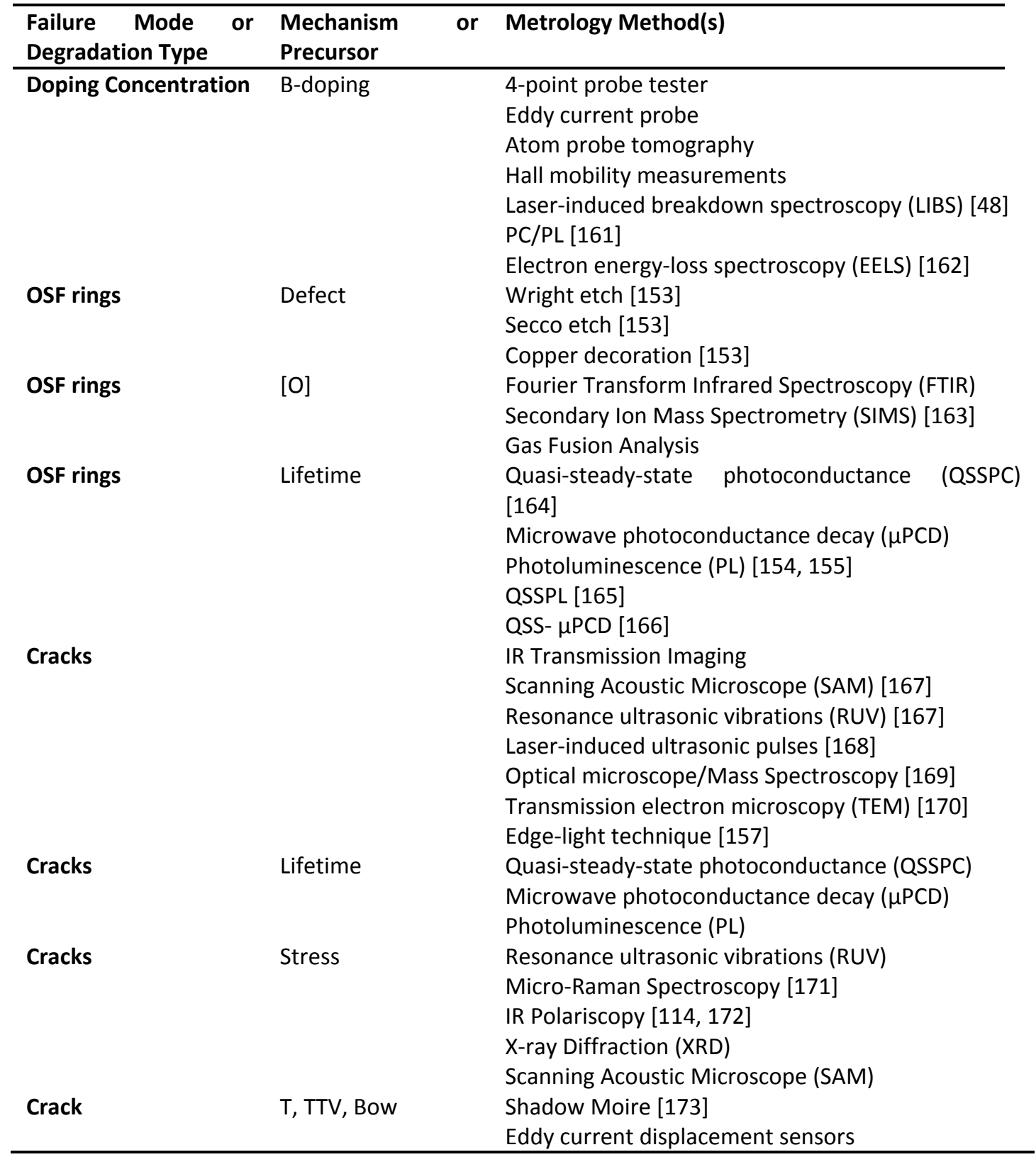




\begin{tabular}{|c|c|c|}
\hline & & Optical and laser sensors \\
\hline & & Capacitive sensors \\
\hline & & Linear inductive sensors \\
\hline & & Draw wire displacement sensors \\
\hline & & Laser micrometer \\
\hline & & 2D/3D profile sensors (scanner) \\
\hline \multirow[t]{3}{*}{ Crack } & Oxygen & Photoluminescence imaging [171] \\
\hline & & Nomarski optical microscopy [171] \\
\hline & & Fourier transform infrared (FTIR) \\
\hline \multirow[t]{7}{*}{ Defect } & Dislocation & Defect etching \\
\hline & & Scanning defect mapping system (SDMS) [174] \\
\hline & & $\begin{array}{l}\text { Quasi-steady-state photoconductance (QSSPC) } \\
\text { [164] }\end{array}$ \\
\hline & & Photoluminescence (PL) $[106,175-177]$ \\
\hline & & Scanning electron microscopy (SEM) [178] \\
\hline & & PVScan [179] \\
\hline & & Transmission electron microscopy (TEM) [180] \\
\hline \multirow[t]{4}{*}{ Defect } & Lifetime & Quasi-steady-state photoconductance (QSSPC) \\
\hline & & Microwave photoconductance decay ( $\mu \mathrm{PCD}$ ) \\
\hline & & Photoluminescence (PL) [175] \\
\hline & & Surface photovoltage (SPV) [160] \\
\hline \multirow[t]{7}{*}{ LID } & Metal Impurities & X-ray fluorescence analysis (XRF) \\
\hline & & Energy Dispersive X-Ray Spectroscopy (EDX) [113] \\
\hline & & Cathodoluminescence $(\mathrm{CL})$ \\
\hline & & Laser-induced breakdown spectroscopy (LIBS) [48] \\
\hline & & Photoluminescence (PL) $[158,159]$ \\
\hline & & Transmission electron microscopy (TEM) \\
\hline & & Surface photovoltage (SPV) [160] \\
\hline LID & B-O Complexes & Surface photovoltage (SPV) [160] \\
\hline \multirow[t]{2}{*}{ LID } & Lifetime & Quasi-steady-state photoconductance (QSSPC) \\
\hline & & Microwave photoconductance decay ( $\mu \mathrm{PCD})$ \\
\hline \multirow[t]{10}{*}{ Shunts } & Metal Impurities & X-ray fluorescence spectroscopy (XRF) \\
\hline & & Energy Dispersive X-Ray Spectroscopy (EDX) [113] \\
\hline & & Cathodoluminescence $(\mathrm{CL})$ \\
\hline & & Laser-induced breakdown spectroscopy (LIBS) [48] \\
\hline & & Photoluminescence (PL) $[158,159]$ \\
\hline & & $\begin{array}{l}\text { Vapor phase decomposition droplet collection } \\
\text { (VPD-DC) [181] }\end{array}$ \\
\hline & & $\begin{array}{l}\text { Total reflection X-ray fluorescence spectroscopy } \\
\text { (TXRF) [181] }\end{array}$ \\
\hline & & $\begin{array}{l}\text { Modified inductively coupled plasma mass } \\
\text { spectrometry (ICP-MS) [181] }\end{array}$ \\
\hline & & Liquid surface etching (LSE) followed by TXRF [181] \\
\hline & & X-ray Absorption Near-Edge Spectroscopy (XANES) \\
\hline Shunts & $\begin{array}{l}\text { Inclusions, } \\
\text { Precipitates }\end{array}$ & Infrared transmission microscopy (IRTM) [182] \\
\hline \multirow[t]{3}{*}{ Shunts } & Lifetime & Quasi-steady-state photoconductance (QSSPC) \\
\hline & & Photoconductance decay $(\mu \mathrm{PCD})$ \\
\hline & & Photoluminescence (PL) \\
\hline \multirow[t]{3}{*}{ PID } & Shunts / Stacking & Scanning electron microscopy (SEM) [152] \\
\hline & fault & Transmission electron microscopy (TEM) [152] \\
\hline & & Energy Dispersive X-Ray Spectroscopy (EDX) [152] \\
\hline
\end{tabular}




\begin{tabular}{|c|c|c|}
\hline PID & $\mathrm{SiN}$ & $\begin{array}{l}\text { ToF SIMS [152] } \\
\text { Infrared transmission microscopy (IRTM) [182] }\end{array}$ \\
\hline \multirow[t]{2}{*}{ Wire Breaking } & {$[\mathrm{C}]$ in SiC } & Fourier Transform Infrared Spectroscopy (FTIR) \\
\hline & & Secondary lon Mass Spectrometry (SIMS) [163] \\
\hline \multirow[t]{5}{*}{ Wafering Damage } & Surface Quality & Scanning electron microscopy (SEM) [113] \\
\hline & & Atomic Force Microscopy (AFM) \\
\hline & & Confocal laser Profilometer [109] \\
\hline & & $\begin{array}{l}\text { Quasi-steady-state photoconductance (QSSPC) } \\
\text { [183] }\end{array}$ \\
\hline & & Electron spin resonance (ESR) spectroscopy \\
\hline \multirow[t]{2}{*}{ Wafering Damage } & Crystal phase & Raman Spectroscopy \\
\hline & & Electron backscatter diffraction (EBSD) \\
\hline \multirow[t]{2}{*}{ Grain } & Physical & Grain analysis system (GAS) [184] \\
\hline & Characteristics & Scanning electron microscopy (SEM) \\
\hline \multirow[t]{5}{*}{ Grain } & Orientation & Electron backscatter diffraction (EBSD) \\
\hline & & Optical methods [185] \\
\hline & & Photoluminescence (PL) $[105,186]$ \\
\hline & & X-ray Diffraction (XRD) \\
\hline & & IR Reflection \\
\hline \multirow[t]{6}{*}{ Grain } & Electrical Activity & Photoluminescence (PL) \\
\hline & ( $\Sigma 3$ or twin $\mathrm{GB}-$ & \\
\hline & Electrically & \\
\hline & inactive) (Low & \\
\hline & angle $\quad \mathrm{GB} \quad-$ & \\
\hline & Electrically active). & \\
\hline Breakage & Failure Strength & Optical cavity furnace $[179,187]$ \\
\hline
\end{tabular}

\subsubsection{Metrology Techniques for New Wafering Methodologies and Substrates}

Evidently, the metrology strategy for wafering is highly dependent on the wafering methodology considered (i.e. traditional wafer sawing versus "kerfless" wafering).

Epitaxial silicon wafers. Measuring the concentration of $B$, the main doping impurity in p-type silicon, is not important for traditional wafering operations; however, such quality control measurements may prove necessary for creating a uniform porous silicon layer electrochemically since this requires the use of highly $p$-doped silicon substrates.

Implant / cleave wafers. Optical microscopy with heating a stage and mass spectroscopy are useful in characterizing hydrogen-implanted silicon used in the implant/cleave wafering scheme, and it was found that the amount of gas released when splitting the material is proportional to the surface area of microcracks [169]. Transmission electron microscopy has also been used in connection to the implant/cleave wafering scheme [170]. SIMS is used for characterizing the proton range distribution into the silicon [122]. Thermal and visible-light imaging techniques are used for temperature measurement and process control [122].

Thin wafers. It is expected that wafers are going to get thinner in the future. Coletti et al. describes that future devices using thin wafers will be more sensitive to impurity content than current state-of-the-art devices [10]. There is a need for cleaner materials and processes as well as fast and in-line metrology for impurity characterization. Using photoluminescence is certainly attractive [158]. An alternative would be laser-induced breakdown spectroscopy for the multi-elemental analytical characterization of silicon 
samples; it is non-destructive, fast, highly sensitive to multiple elements, and does not require any sample preparation [48].

N-type wafers. The popular belief is that the $\mathrm{n}$-type wafers for future novel architecture will ease the requirements on metallic impurities from a performance point of view. However, this is not the case when metallic impurities other than iron are considered [11]. It would be interesting to see what new reliability challenges arise with the use of $n$-type wafers. As these wafers become more prevalent, new metrology techniques sensitive to "killer impurities" in n-type wafers will need to be developed.

\subsubsection{Gap Analysis}

This section is intended to provide an assessment of the current state of understanding in being able to connect metrology data to reliability/durability in the field and identify areas of improvement that should be considered by the PV R\&D community.

Stress Measurements. It is well understood that stress can lead to cracks, which are triggers for shunts, and that they can also propagate under thermal and mechanical loading, leading to reliability concerns including breakage. The stress levels inside wafers, whether tensile or compressive, are not routinely characterized on manufacturing lines if at all. There are certainly several interesting metrology techniques that can measure stress within wafers at line speed and therefore lend themselves very nicely to large scale manufacturing. Two examples are resonant ultrasonic vibrations (RUV) and infrared polariscopy (IRP) [114, 172]. Instead of measuring stress, a slightly different approach is to measure the stress budget by submitting an incoming wafer to an elastic stress similar in magnitude to the levels experienced during cell and module fabrication with the hypothesis that if the wafer survives the test, it is fit for fabrication. This is in effect the principle behind the optical cavity furnace proposed by the National Renewable Energy Laboratory.

Photoluminescence (PL). Photoluminescence is highly versatile and understandably gaining in popularity. Typically, carriers are excited above the bandgap (wavelength $<1100 \mathrm{~nm}$ ) using a laser at $800 \mathrm{~nm}$, and the photoluminescence signal is measured to detect several types of defects, whether structural (cracks/dislocations) or impurity related (precipitates), at line speed. However, there is much improvement that needs to be made in understanding the PL spectra and how it relates to various types

of defects. Furthermore, PL might not be able to detect accurately certain defects. For example, Type A defects, although difficult to detect with $\mathrm{PL}$, are more detrimental as they are known to exhibit Type II pre-breakdown behavior in reverse bias, resulting hot spots/shunts [188]. While alternative methods have been proposed [189], there is still a need for a metrology technique that can detect Type A defects.

Oxidation-induced stacking fault (OSF) rings. OSF-rings are difficult to characterize before oxidation. They not only affect performance, but they also can affect reliability. The key is to detect the border region between silicon self-interstitials (outside the ring) and vacancies (inside this ring). Photoluminescence and other in-line techniques are not very good at detecting this region although it is possible [153]. Currently, only off-line techniques such as Cu-decoration, Secco etch, and Wright etch can do a satisfactory job. There is a need for an in-line metrology that can identify regions between silicon self-interstitials and vacancies. 
Epitaxial silicon (Epi-si) wafers. Epi-si wafers are also gaining in popularity recently. An adequate measurement of porosity in the porous layers in a high through-put environment would be useful. The characteristics of the porous layer are important in order to properly release the free standing epi-layer from the parent substrate with high yield.

Diamond wires. Diamond wires are becoming more and more popular. SiC clusters formed during multicrystalline ingot growth can results in wire breakage. Also, the wires are continually decreasing in diameter in order to reduce the kerf loss and support the trend of decreasing wafer thickness, which in turn increases the chances of the wire breakage. Thus, monitoring the level of wear in the diamond wires is critical. If the wire breaks during sawing, the entire ingot is lost. Furthermore, it was noted in the case of slurry wire sawing that the wire tension in the wire web is lost during ingot cutting. Perhaps the use of metrology to monitor the wire tension would be useful as well [190].

High-speed evaluation of crystal structure/orientation. There are some advantages in measuring crystal structure and orientation for mono-Si wafers as well as grain size and orientation for quasimonocrystalline and multi-Si wafers. This information is useful in determining the quality of the damage etch removal, or in determining the appropriate chemistry for texturing, or again the appropriate recipe for the passivation of solar cell surfaces.

In-line minority carrier lifetime measurements. It is desirable to have a high-throughput lifetime measurement on as-cut wafers, and being able to separate lifetime due to bulk vs. surface recombination.

High speed/real-time identification of areas with high defect density. Determining the structural defect density (SDD) usually takes hours and relies on etching and laser scanning. PL is much faster; however, it is believed that PL is not well equipped to detect type A defects after antireflection coating (ARC) and prior to cell processing [191]. Recently, a new proposed approach relies on chemical treatment and image processing, boasting minutes as opposed to hours of processing time [189]. Even shorter processing times would be desirable.

Scan density during inline inspection of wafers. Determine optimal scan density and cost versus need (value-cost curve). This would help also in evaluating the uniformity of wafers from different polysilicon sources, ingots, bricks, etc.

Methodology for surface (metal) contaminants. This is more important with new cell architectures. Methods for determination of surface metal contamination have been well established for mirror polished wafers in the microelectronics world; however, they cannot be easily applied to PV wafers because of the large roughness. The following methods have been proposed for PV: vapor-phase decomposition droplet collection with total reflection X-ray fluorescence spectroscopy (VPD-DC-TXRF), a modified inductively coupled plasma mass spectrometry (ICP-MS) for non-polished wafer surfaces, and liquid surface etching (LSE) followed by TXRF analysis. There is a need for a fast and in-line method to characterize the quality of a wafer surface before cell fabrication [181].

Compensated doping. There may be a need to measure all dopant concentrations in addition to just resistivity, desirably in-line and using full wafer mapping. It was demonstrated that the initial degradation of solar modules seemed to be influenced by the silicon feedstock (in this case SoG-UMG) 
used in wafer production; while the long term degradation mechanisms seemed not to be [192]. LID could be permanently deactivated for SoG-UMG [193]. Furthermore, uneven distribution of dopants has been shown to have a remarkable effect on the residual stress and therefore breakage [194].

\section{Summary and Conclusion}

The process steps for making silicon substrates for PV cells include feedstock, ingot, and wafer production. The final reliability/durability of the PV modules in the field can be impacted during or as a result of each of these process steps. It is desirable to identify metrology techniques that can be performed during manufacturing to predict failures or unacceptable degradation for PV modules in the field.

\subsection{Feedstock Production}

Several different failure modes can develop during or as a result of the feedstock production processes. When a fluidized bed reactor (FBR) is used, seeds and fine particles can form, which can result in the formation of dislocations and inhibit proper crystal growth, and can negatively impact durability. However, the major reliability challenge that can occur as a result of the feedstock production processing step is the presence of impurities. Depending on the process used, there are several different sources of impurities. Where possible, impurities and their accepted levels for solar grade silicon have been identified in this article.

Prior to crystal growth, the typical metrology carried out on feedstock involves elemental analysis. Although many characterization techniques have proven to be useful in predicting potential future reliability challenges, direct sampling using glow discharge mass spectrometry and secondary ion mass spectrometry have been identified as the most sensitive analytical methods available today for routine analyses of PV grade materials. Because many elemental analysis techniques are expensive and/or take a significant amount of time, it is not possible to examine every chunk, granule, or fines. Therefore, a fast and accurate method, such as laser-induced breakdown spectroscopy could be useful. In addition, to overcome FBR shortcomings, new reactor design should be investigated.

\subsection{Ingot Production}

Ingot production processes can result in many different types of failure modes. Depending on the grade of silicon, LID is a major reliability challenge that can result from ingot production, with UMG mc-Si, and UMG mono-Si being the most susceptible. Several steps have been taken to mitigate LID during cell fabrication and post module fabrication. Crystallographic defects and material-induced and fieldinduced shunts are other reliability challenges that can occur as a result of ingot production. Several of the processing steps in ingot production can also result in crack formation, which will also impact reliability and durability.

Several metrology techniques to predict the failure modes that occur as a result of ingot production exist. To predict LID, metrology techniques focus on identifying levels of $B$ (or other dopant) and $O$ via the measurement of the base resistivity, net doping, and impurity segregation. Metrology techniques to predict shunt formation identify phenomena including impurity segregation and crystallographic defects. Cracks are identified by examining residual stress, edge roughness, imaging, and lifetime. 
There are several types of metrology techniques that could be potentially useful for identifying failure modes that are not currently available and should be developed. A fast, quantitative method of measuring dislocations in ingots is desirable for 3D dislocation mapping. A fast imaging solution for inline metrology is also needed for both residual stress imaging and visual inspection.

\subsection{Wafer Production}

Many reliability issues can occur as a result of wafer production. Stress induced during wafering can result in cracks and breakage. Micro-cracking in wafers is unavoidable, and its impact on durability can range from minor to catastrophic failure, including wafer or solar cell breakage and shunt formation. Breakage can also be caused by scratches, variations in thickness, ditches formed by SiC precipitates, residual stress, and warping. Shunting can result in hot spots formation, which can have severe impacts on module durability.

Numerous metrology techniques exist for the characterization of failure modes that can result from wafer production. Cracks can be characterized using IR imaging, photoluminescence, and resonance ultrasonic vibrations. Residual stress can be evaluated in-line using infrared polariscopy.

There are several areas where improvements could be made to metrology techniques that could improve the connection between wafering steps and PV module reliability/durability, for both traditional and new wafer processes. For example, with new cell architectures, in-line methods to determine surface metal contamination of PV wafers must be developed. Proposed methods include VPD-DC-TXRF, ICP-MS, and LSE-TXRF. In addition, although stress developed during wafering can trigger many reliability concerns, it is not routinely characterized on manufacturing lines. Metrology techniques that can measure stress within wafers in line, such as RUV and IRP could be useful in predicting field durability as a result of wafering.

\subsection{Acknowledgments}

The authors acknowledge Jan Maurits, John Holder, Daniel Cunningham, Bhushan Sopori and Steven Johnston for their helpful comments.

This material is based upon work supported by the U.S. Department of Energy, Office of Energy Efficiency and Renewable Energy, in the Solar Energy Technologies Program, under Award Number DEEE0004947.

\subsection{Glossary of Acronyms}

\begin{tabular}{ll}
\hline Acronym & Definition \\
\hline Al & Aluminum \\
AES & Auger electron spectroscopy \\
AFM & Atomic force microscopy \\
ARC & Antireflection coating \\
As & Arsenic \\
Au & Gold \\
B & Boron \\
C & Carbon \\
\hline
\end{tabular}




\begin{tabular}{|c|c|}
\hline $\mathrm{Ca}$ & Calcium \\
\hline $\mathrm{Cd}$ & Cadmium \\
\hline $\mathrm{CL}$ & Cathodoluminescence \\
\hline Co & Cobalt \\
\hline $\mathrm{Cr}$ & Chromium \\
\hline c-Si & Crystalline silicon \\
\hline $\mathrm{Cu}$ & Copper \\
\hline $\mathrm{CZ}$ & Czochralski \\
\hline DC & Direct Chlorination \\
\hline DCS & Dichlorosilane \\
\hline DLTS & Deep-level transient spectroscopy \\
\hline DS & Directional Solidification \\
\hline EBIC & Electron beam induced current \\
\hline EBSD & Electron backscattering diffraction \\
\hline EDX & Energy dispersive X-ray spectroscopy \\
\hline EELS & Electron energy-loss spectroscopy \\
\hline EFG & Edge-defined film-fed growth \\
\hline EG-Si & Electronic grade polysilicon \\
\hline EMC & Electromagnetic Casting \\
\hline Epi-si & Epitaxial silicon \\
\hline ESR & Electron spin resonance \\
\hline FBR & Fluidized bed reactor \\
\hline $\mathrm{Fe}$ & Iron \\
\hline FTIR & Fourier transform infrared spectroscopy \\
\hline FZ & Float Zone \\
\hline $\mathrm{Ga}$ & Gallium \\
\hline GB & Grain boundaries \\
\hline GDMS & Glow discharge mass spectrometry \\
\hline $\mathrm{H}$ & Hydrogen \\
\hline $\mathrm{HC}$ & HydroChlorination \\
\hline $\mathrm{HF}$ & Hydrofluoric acid \\
\hline HRG & Horizontal ribbon growth \\
\hline ICP-MS & Inductively couple plasma-mass spectroscopy \\
\hline ICP-OES & Inductively couple plasma-mass spectroscopy \\
\hline $\ln$ & Indium \\
\hline IR & Infrared \\
\hline IRP & Infrared polariscopy \\
\hline IRTM & Infrared transmission microscopy \\
\hline ITRPV & International Technology Roadmap for Photovoltaic \\
\hline K & Potassium \\
\hline LIBS & Light induced breakdown spectroscopy \\
\hline LID & Light Induced Degradation \\
\hline $\mathrm{Mg}$ & Magnesium \\
\hline MG-Si & Metallurgical grade polysilicon \\
\hline $\mathrm{mm}$ & Millimeter \\
\hline $\mathrm{Mn}$ & Manganese \\
\hline Mo & Molybdenum \\
\hline Mono-Si & Monocrystalline silicon \\
\hline Multi-si & Multicrystalline silicon \\
\hline $\mathrm{N}$ & Nitrogen \\
\hline $\mathrm{Na}$ & Sodium \\
\hline NAA & Neutron activation analysis \\
\hline
\end{tabular}




\begin{tabular}{|c|c|}
\hline $\mathrm{Nb}$ & Niobium \\
\hline nc-Si & Nanocrystalline silicon \\
\hline $\mathrm{Ni}$ & Nickel \\
\hline $\mathrm{nm}$ & Nanometer \\
\hline $\mathrm{O}$ & Oxygen \\
\hline OSF & Oxygen-induced stacking faults \\
\hline $\mathrm{P}$ & Phosphorus \\
\hline PEG & Polyethylene glycol \\
\hline PL & Photoluminescence \\
\hline PV & Photovoltaic \\
\hline QSSPC & Quasi-steady-state photoconductance \\
\hline RGS & Ribbon growth on a substrate \\
\hline RUV & Resonance ultrasonic vibrations \\
\hline SAM & Scanning Acoustic Microscope \\
\hline $\mathrm{Sb}$ & Antimony \\
\hline SDD & Structural defect density \\
\hline SEM & Scanning electron microscopy \\
\hline $\mathrm{SiC}$ & Silicon carbide \\
\hline SIMS & Secondary ion mass spectrometry \\
\hline SoG-Si & Solar grade polysilicon \\
\hline SPV & Surface photovoltage \\
\hline SRG & String ribbon growth \\
\hline STC & Silicon tetrachloride \\
\hline SXR & Synchrotron X-ray radiography \\
\hline TBS & Tribromosilane \\
\hline TCS & Trichlorosilane \\
\hline TEM & Transmission electron microscopy \\
\hline $\mathrm{Ti}$ & Titanium \\
\hline TID & Temperature induced degradation \\
\hline TTV & Total thickness variation \\
\hline UMG-Si & Upgraded metallurgical grade polysilicon \\
\hline UNICAMP & State University of Campinas \\
\hline$\mu$-cracks & Micro-cracks \\
\hline$\mu \mathrm{c}-\mathrm{Si}$ & Microcrystalline silicon \\
\hline$\mu \mathrm{PCD}$ & Microwave photoconductance decay \\
\hline v & Vanadium \\
\hline W & Tungsten \\
\hline WEB & Dendritic web growth \\
\hline XPS & X-ray photoelectron spectroscopy \\
\hline XRD & X-ray diffraction \\
\hline XRF & X-ray fluorescence spectroscopy \\
\hline $\mathrm{Zn}$ & Zinc \\
\hline $\mathrm{Zr}$ & Zirconium \\
\hline
\end{tabular}




\section{References}

[1] Bye G, Ceccaroli B. Solar grade silicon: Technology status and industrial trends. Solar Energy Materials and Solar Cells. 2014;130:634-46.

[2] Arnberg L, Di Sabatino M, Øvrelid EJ. State-of-the-art growth of silicon for PV applications. Journal of Crystal Growth. 2012;360:56-60.

[3] Fisher G, Seacrist MR, Standley RW. - Silicon Crystal Growth and Wafer Technologies. 2012;- 100:1474.

[4] Surek T. Crystal growth and materials research in photovoltaics: progress and challenges. Journal of Crystal Growth. 2005;275:292-304.

[5] Gopala Krishna Murthy HS. Review: Evolution and present status of silicon carbide slurry recovery in silicon wire sawing. Resources, Conservation \& Recycling. 2015.

[6] Wu H. Wire sawing technology: A state-of-the-art review. Precision Engineering.

[7] Abdelhamid M, Singh R, Omar M. - Review of Microcrack Detection Techniques for Silicon Solar Cells. 2014;- 4:- 524.

[8] Istratov AA, HiesImair H, Vyvenko OF, Weber ER, Schindler R. Defect recognition and impurity detection techniques in crystalline silicon for solar cells. Solar Energy Materials and Solar Cells. 2002;72:441-51.

[9] Davis KO, Brooker RP, Seigneur HP, Rodgers M, Rudack AC, Schoenfeld WV. Pareto analysis of critical challenges for emerging manufacturing technologies in silicon photovoltaics. Solar Energy. 2014;107:681-91.

[10] Coletti G. Sensitivity of state-of-the-art and high efficiency crystalline silicon solar cells to metal impurities. Progress in Photovoltaics: Research and Applications. 2013;21:1163-70.

[11] Schmidt J, Lim B, Walter D, Bothe K, Gatz S, Dullweber T, et al. Impurity-Related Limitations of NextGeneration Industrial Silicon Solar Cells. Photovoltaics, IEEE Journal of. 2013;3:114-8.

[12] del Coso G, del Cañizo C, Sinke WC. The impact of silicon feedstock on the PV module cost. Solar Energy Materials and Solar Cells. 2010;94:345-9.

[13] Karazhanov SZ. Impurity photovoltaic effect in indium-doped silicon solar cells. Journal of Applied Physics. 2001;89:4030-6.

[14] Buonassisi T, Istratov AA, Pickett MD, Rakotoniaina JP, Breitenstein O, Marcus MA, et al. Transition metals in photovoltaic-grade ingot-cast multicrystalline silicon: Assessing the role of impurities in silicon nitride crucible lining material. Journal of Crystal Growth. 2006;287:402-7.

[15] Kvande R, Arnberg L, Martin C. Influence of crucible and coating quality on the properties of multicrystalline silicon for solar cells. Journal of Crystal Growth. 2009;311:765-8.

[16] Macdonald D, Tan J. Impurities in solar-grade silicon. 2007. p. 68000X-X-7.

[17] Pizzini S. Bulk solar grade silicon: how chemistry and physics play to get a benevolent microstructured material. Appl Phys A. 2009;96:171-88.

[18] Forster M, Dehestru B, Thomas A, Fourmond E, Einhaus R, Cuevas A, et al. Compensation engineering for uniform n-type silicon ingots. Solar Energy Materials and Solar Cells. 2013;111:146-52.

[19] Fishman OS. SOLAR SILICON. Advanced Materials \& Processes. 2008;166:39-40.

[20] Aasly K. Properties and Behabior of Quartz for the Silicon Process [Dissertation]. Norway: Norwegian UNiversity of Science and Technology; 2008.

[21] Chakraborty A. Thermodynamic Approach. Phase Transformation of Kaolinite Clay: Springer India; 2014. p. 115-23.

[22] Braga AFB, Moreira SP, Zampieri PR, Bacchin JMG, Mei PR. New processes for the production of solar-grade polycrystalline silicon: A review. Solar Energy Materials and Solar Cells. 2008;92:418-24. 
[23] Perez-Mariano J, Moro L, Kai L, Hornbostel M, Nagar A, Xie B, et al. Production of low-cost solargrade silicon by reduction of $\mathrm{SiF}<\mathrm{inf}>4</ \mathrm{inf}>$ gas with sodium: Technical and industrial developmental status. Photovoltaic Specialists Conference (PVSC), 2010 35th IEEE2010. p. 002198-203.

[24] Tandjaoui A, Mangelinck-Noel N, Reinhart G, Billia B, Lafford T, Baruchel J. Investigation of grain boundary grooves at the solid-liquid interface during directional solidification of multi-crystalline silicon: in situ characterization by X-ray imaging. Journal of Crystal Growth. 2013;377:203-11.

[25] R. Einhaus JK, F. Cocco, Y. Caratini, D. Bernou, D. Sarti, G. Rey, R. Monna, C. Trassy, J. Degoulange, Y. Delannoy, S. B. Martinuzzi, I. Perichaud, M. C. Record, P. Rivat. PHOTOSIL - Simplified Production of Solar Silicon from Metallurgical Silicon. 21st European Photovoltaic Solar Energy Conference. Dresden : Germany 2006.

[26] Yuge N, Abe M, Hanazawa K, Baba H, Nakamura N, Kato Y, et al. Purification of metallurgical-grade silicon up to solar grade. Progress in Photovoltaics: Research and Applications. 2001;9:203-9.

[27] Wang TY, Lin YC, Tai CY, Fei CC, Tseng MY, Lan CW. Recovery of silicon from kerf loss slurry waste for photovoltaic applications. Progress in Photovoltaics: Research and Applications. 2009;17:155-63.

[28] Maurits J. PV Feedstock Costs-Five Year Outlook. Golden, Colorado: National Renewable Energy Laboratory; 2003.

[29] Herrick CS, Krieble JG. High-Purity Silicon from an lodide Process Pilot Plant. Journal of The Electrochemical Society. 1960;107:111-7.

[30] Ciszek TF, Wang TH, Page MR, Bauer RE, Landry MD. Solar-grade silicon from metallurgical-grade silicon via iodine chemical vapor transport purification. Conf Rec IEEE Photovoltaic Spec Conf. 2002;29th:206-9.

[31] ARJAN CIFTJA TAE, MERETE TANGSTAD. Refining and Recycling of Silicon: A Review. In: Tech NUoSa, editor. Trondheim, Norway2008.

[32] Schumacher JC. High purity silicon. J. C. Schumacher Co., USA . 1978. p. 7 pp.

[33] Woditsch P, Koch W. Solar grade silicon feedstock supply for PV industry. Solar Energy Materials and Solar Cells. 2002;72:11-26.

[34] Hofstetter J, Lelièvre JF, del Cañizo C, Luque A. Acceptable contamination levels in solar grade silicon: From feedstock to solar cell. Materials Science and Engineering: B. 2009;159-160:299-304.

[35] Kraiem J, Drevet B, Cocco F, Enjalbert N, Dubois S, Camel D, et al. High performance solar cells made from $100 \%$ UMG silicon obtained via the PHOTOSIL process. Photovoltaic Specialists Conference (PVSC), 2010 35th IEEE2010. p. 001427-31.

[36] Degoulange J, Périchaud I, Trassy C, Martinuzzi S. Multicrystalline silicon wafers prepared from upgraded metallurgical feedstock. Solar Energy Materials and Solar Cells. 2008;92:1269-73.

[37] Teng C, Youwen Z, Zhiyuan D, Tong L, Jun W, Hui X. Analysis of solar cells fabricated from UMG-Si purified by a novel metallurgical method. Semiconductor Science and Technology. 2013;28:015024.

[38] Pires JCS, Otubo J, Braga AFB, Mei PR. The purification of metallurgical grade silicon by electron beam melting. Journal of Materials Processing Technology. 2005;169:16-20.

[39] Wang TY, Lin YC, Tai CY, Sivakumar R, Rai DK, Lan CW. A novel approach for recycling of kerf loss silicon from cutting slurry waste for solar cell applications. Journal of Crystal Growth. 2008;310:3403-6.

[40] Sarti D, Einhaus R. Silicon feedstock for the multi-crystalline photovoltaic industry. Solar Energy Materials and Solar Cells. 2002;72:27-40.

[41] Ceccaroli B, Lohne O, Øvrelid EJ. New advances in polysilicon processes correlating feedstock properties and good crystal and wafer performances. physica status solidi (c). 2012;9:2062-70.

[42] Filtvedt WO, Holt A, Ramachandran PA, Melaaen MC. Chemical vapor deposition of silicon from silane: Review of growth mechanisms and modeling/scaleup of fluidized bed reactors. Solar Energy Materials and Solar Cells. 2012;107:188-200.

[43] Herrick CS, Woodruff DW. The Homogeneous Nucleation of Condensed Silicon in the Gaseous $\mathrm{Si}-\mathrm{H}-\mathrm{Cl}$ System. Journal of The Electrochemical Society. 1984;131:2417-22. 
[44] Hockett RS. Analytical Techniques for PV Si Feedstock Evaluation. Evans Analytical Group.

[45] C. Michellon KP, M. Kasik, R.S. Hockett. Production Support and Process Control of PV Materials by Direct Sampling High-Resolution Glow Discharge Mass Spectrometry Methods. 23rd European Photovoltaic Solar Energy Conference. Valencia, Spain2008.

[46] Tajima M, Iwata Y, Okayama F, Toyota H, Onodera H, Sekiguchi T. Deep-level photoluminescence due to dislocations and oxygen precipitates in multicrystalline Si. Journal of Applied Physics. 2012;111:113523-6.

[47] Nærland TU, Arnberg L, Holt A. Origin of the low carrier lifetime edge zone in multicrystalline PV silicon. Progress in Photovoltaics: Research and Applications. 2009;17:289-96.

[48] Darwiche S, Benmansour M, Eliezer N, Morvan D. Laser-induced breakdown spectroscopy for photovoltaic silicon wafer analysis. Progress in Photovoltaics: Research and Applications. 2012;20:46371.

[49] Duchamp M, Boothroyd CB, Kovács A, Kadkhodazadeh S, Kasama T, Moreno MS, et al. Mapping boron in silicon solar cells using electron energy-loss spectroscopy. Journal of Physics: Conference Series. 2011;326:012052.

[50] Nakamura M, Murakami S, Udono H. Copper centers in copper-diffused n-type silicon measured by photoluminescence and deep-level transient spectroscopy. Applied Physics Letters. 2012;101:042113-4.

[51] Hwang LL, Bucci J, McCormick JR. Measurement of Carbon Concentration in Polycrystalline Silicon Using FTIR. Journal of The Electrochemical Society. 1991;138:576-81.

[52] Serra JM, Pinto CR, Silva JA, Brito MC, Alves JM, Vallêra AM. The silicon on dust substrate path to make solar cells directly from a gaseous feedstock. Semiconductor Science and Technology. 2009;24:045002.

[53] Masolin A, Simoen E, Kepa J, Stesmans A. Defects in Si foils fabricated by spalling at low temperature: electrical activity and atomic nature. Journal of Physics D: Applied Physics. 2013;46:155501.

[54] Zhou $X$, Huang $\mathrm{H}$. Numerical simulation of $\mathrm{Cz}$ crystal growth in rotating magnetic field with crystal and crucible rotations. Journal of Crystal Growth. 2012;340:166-70.

[55] Tachibana T, Sameshima T, Kojima T, Arafune K, Kakimoto K, Miyamura Y, et al. Evaluation of defects generation in crystalline silicon ingot grown by cast technique with seed crystal for solar cells. Journal of Applied Physics. 2012;111:-.

[56] Fukuzawa $M$, Kashiwagi $R$, Yamada $M$, Hirasawa T. Residual strain distribution in casting ingot of multi-crystalline silicon. Energy Procedia. 2011;3:13-6.

[57] Pizzini S, Acciarri M, Binetti S. From electronic grade to solar grade silicon: chances and challenges in photovoltaics. physica status solidi (a). 2005;202:2928-42.

[58] Kvande R, Geerligs L, Coletti G, Arnberg L, Di Sabatino M, $\varnothing$ vrelid EJ, et al. Distribution of iron in multicrystalline silicon ingots. Journal of Applied Physics. 2008;104:-.

[59] Tandjaoui A, Mangelinck-Noël N, Reinhart G, Furter JJ, Billia B, Lafford T, et al. Real Time Observation of the Directional Solidification of Multicrystalline Silicon: X-ray Imaging Characterization. Energy Procedia. 2012;27:82-7.

[60] Kaneko K, Nakagawa K, Onizuka T, Sasatani K-i, Kubo N, Kida M. Recent status on electromagnetic casting. 16 th Workshop on Crystalline Silicon Solar Cells and Modules: Materials and Processes2006. p. 2.

[61] Gu X, Yu X, Guo K, Chen L, Wang D, Yang D. Seed-assisted cast quasi-single crystalline silicon for photovoltaic application: Towards high efficiency and low cost silicon solar cells. Solar Energy Materials and Solar Cells. 2012;101:95-101.

[62] Ervik T, Stokkan G, Buonassisi T, Mjøs $\varnothing$, Lohne O. Dislocation formation in seeds for quasimonocrystalline silicon for solar cells. Acta Materialia. 2014;67:199-206. 
[63] Kaden T, Petter K, Bakowskie R, Ludwig Y, Lantzsch R, Raschke D, et al. Analysis of Mono-cast Silicon Wafers and Solar Cells on Industrial Scale. Energy Procedia. 2012;27:103-8.

[64] Smirnov AD, Kalaev VV. Analysis of impurity transport and deposition processes on the furnace elements during $\mathrm{Cz}$ silicon growth. Journal of Crystal Growth. 2009;311:829-32.

[65] Su W, Zuo R, Mazaev K, Kalaev V. Optimization of crystal growth by changes of flow guide, radiation shield and sidewall insulation in Cz Si furnace. Journal of Crystal Growth. 2010;312:495-501.

[66] K.M. Broek IJB, M.J. Jansen, N.J.C.M. van der Borg, W. Eerenstein. Light and current induced degradation in p-type multi-crystalline cells and development of an inspection method and a stabilisation method. 27th EU PVSEC. Frankfurt, Germany2012.

[67] Voronkov VV, Falster R, Batunina AV, Macdonald D, Bothe K, Schmidt J. Lifetime degradation mechanism in boron-doped Czochralski silicon. Energy Procedia. 2011;3:46-50.

[68] Carvalho A, Santos P, Coutinho J, Jones R, Rayson MJ, Briddon PR. Light induced degradation in B doped Cz-Si solar cells. Phys Status Solidi A. 2012;209:1894-7.

[69] Murin LI, Tolkacheva EA, Markevich VP, Peaker AR, Hamilton B, Monakhov E, et al. The oxygen dimer in Si: Its relationship to the light-induced degradation of Si solar cells? Applied Physics Letters. 2011;98:182101-3.

[70] S. Pingel DK, O. Frank, T. Geipel, Y. Zemen, B. Striner, J. Berghold. Initial degradation of industrial silicon solar cells in solar panels. 25th EU PVSEC. Valencia, Spain2010.

[71] Lindroos J, Yli-Koski M, Haarahiltunen A, Savin H. Room-temperature method for minimizing lightinduced degradation in crystalline silicon. Applied Physics Letters. 2012;101:232108-3.

[72] Savin H, Yli-Koski M, Haarahiltunen A. Role of copper in light induced minority-carrier lifetime degradation of silicon. Applied Physics Letters. 2009;95:152111-3.

[73] Chen P, Yu XG, Wu YC, Zhao JJ, Yang DR. Light-induced degradation in n-type Czochralski silicon by boron-doping and thermal donor compensation. Journal of Applied Physics. 2012;112.

[74] Søndenå R, Søiland AK, Angelskår H, Holt A. Light Induced Degradation in mc-Si Based on Compensated Silicon. Energy Procedia. 2012;27:70-5.

[75] Tayyib M, Rao YH, Ramanjaneyulu M, Surendra TS, Odden JO, Saetre TO. Initial light-induced degradation study of multicrystalline modules made from silicon material processed through different manufacturing routes. Photovoltaic Specialists Conference (PVSC), 2012 38th IEEE2012. p. 002395-9.

[76] Xianpei R, Chao C, Haoran C, Falin H. Light-Induced Degradation in Multicrystalline Silicon Solar Cells Made of Metallurgical Grade Silicon. Power and Energy Engineering Conference (APPEEC), 2012 AsiaPacific2012. p. 1-4.

[77] Ounadjela K, Sidelkheir O, Chun-Sheng J, Al-Jassim MM. Light-induced degradation in upgraded metallurgical-grade silicon solar cells. Photovoltaic Specialists Conference (PVSC), 2012 38th IEEE2012. p. 002739-43.

[78] K. Petter YL, R. Bakowskie, M. Hlusiak, S. Diez, L.L. Ritz, R. Lantzsch, S. Rupp, A. Freudenberg, S. Scholz, V. Hoffmann Latest Results on Production of Solar Cells Using UMG-Si Feedstock. 25th EU PVSEC. Valencia, Spain2010.

[79] Forster M, Dehestru B, Thomas A, Fourmond E, Einhaus R, Cuevas A, et al. Compensation engineering for uniform n-type silicon ingots. Solar Energy Materials and Solar Cells. 2013;111:146-52.

[80] Das A, Rohatgi A. The impact of cell design on light induced degradation in p-type silicon solar cells. Photovoltaic Specialists Conference (PVSC), 2011 37th IEEE2011. p. 000158-64.

[81] Bhushan Sopori PB, Sudhakar Shet, Vishal Mehta, Jeff Binns and Jesse Appel. Understanding LightInduced Degradation of c-Si Solar Cells. 2012 IEEE PVSC. Austin, Texas2012.

[82] Glunz SW, Lee JY, Rein S. Strategies for improving the efficiency of Cz-silicon solar cells. Photovoltaic Specialists Conference, 2000 Conference Record of the Twenty-Eighth IEEE2000. p. 201-4. 
[83] J. Schmidt KB, D. Macdonald, J. Adey, R. Jones, D. W. Palmer. Mechanisms of Light-Induced Degradation in c-Si Solar Cells. The 4th International Symposium on Advanced Science and Technology of Silicon Materials2004.

[84] Dhamrin M, Hashigami H, Saitoh T. Elimination of light-induced degradation with gallium-doped multicrystalline silicon wafers. Progress in Photovoltaics: Research and Applications. 2003;11:231-6.

[85] Lindroos J, Yli-Koski M, Haarahiltunen A, Schubert MC, Savin H. Light-induced degradation in copper-contaminated gallium-doped silicon. physica status solidi (RRL) - Rapid Research Letters. 2013;7:262-4.

[86] Yu XG, Zheng X, Hoshikawa K, Yang DR. Crystal Growth of Indium-Doped Czochralski Silicon for Photovoltaic Application. Jpn J Appl Phys. 2012;51.

[87] Möller C, Lauer K. Light-induced degradation in indium-doped silicon. physica status solidi (RRL) Rapid Research Letters. 2013;7:461-4.

[88] Bianca Lim KB, Vladimir Voronkov, Robert Falster, Jan Schmidt. Light-induced degradation of the carrier lifetime in n-type Czochralski-grown siliscon doped with boron and phosphorus. 26th EU PVSEC. Hamburg, Germany2011.

[89] Dengyuan S, Jingfeng X, Zhiyan H, Gaofei L, Hongfang W, Haijiao A, et al. Progress in n-type Si solar cell and module technology for high efficiency and low cost. Photovoltaic Specialists Conference (PVSC), 2012 38th IEEE2012. p. 003004-8.

[90] Gu X, Yuan S, Yu X, Guo K, Yang D. Dislocation-induced variation of generation kinetics of boronoxygen complexes in silicon. Journal of Crystal Growth. 2012;359:69-71.

[91] Kang MH, Hong J, Cooper I, Ebong A, Rounsaville B, Rohatgi A. Reduction in Light Induced Degradation (LID) in B-doped Cz-Si Solar Cells with SiCxNy Antireflection (AR) Coating. J Electrochem Soc. 2011;158:H724-H6.

[92] De Wolf S, Demaurex B, Descoeudres A, Ballif C. Very fast light-induced degradation of a-Si:H/c$\mathrm{Si}(100)$ interfaces. Physical Review B. 2011;83:233301.

[93] Herguth A, Schubert G, Kaes M, Hahn G. Investigations on the long time behavior of the metastable boron-oxygen complex in crystalline silicon. Progress in Photovoltaics: Research and Applications. 2008;16:135-40.

[94] Breitenstein O, Rakotoniaina JP, Al Rifai MH, Werner M. Shunt types in crystalline silicon solar cells. Progress in Photovoltaics. 2004;12:529-38.

[95] Hejjo ARB, O.; Rakotoniaina, J.P.; Werner, M. INVESTIGATION OF MATERIAL-INDUCED SHUNTS IN BLOCK-CAST MULTICRYSTALLINE SILICON SOLAR CELLS CAUSED BY SiC PRECIPITATE FILAMENTS. 19th EU PVSEC. Paris, France2004.

[96] Wasmer K, Bidiville A, Jeanneret F, Michler J, Ballif C, Van-der-Meer M, et al. Effects of edge defects induced by multi-wire sawing on the wafer strength. 23rd European Photovoltaic Solar Energy Conference. Valencia2008. p. 1305-10.

[97] Borrero-López O, Vodenitcharova T, Hoffman M, Leo AJ. Fracture Strength of Polycrystalline Silicon Wafers for the Photovoltaic Industry. Journal of the American Ceramic Society. 2009;92:2713-7.

[98] Di Sabatino M, Stokkan G. Defect generation, advanced crystallization, and characterization methods for high-quality solar-cell silicon. physica status solidi (a). 2013;210:641-8.

[99] Bellmann MP, Meese EA, Arnberg L. Impurity segregation in directional solidified multi-crystalline silicon. Journal of Crystal Growth. 2010;312:3091-5.

[100] Kamieniecki E. Defect specific photoconductance: Carrier recombination through surface and other extended crystal imperfections. Journal of Applied Physics. 2012;112:063715-8.

[101] R. Zeidler JH, B. Seeber, S. Riepe, H. Höffler, F. Fertig, I. Reis, S. Rein. Tomographic Defect Reconstruction of Multicrystalline Silicon Ingots Using Photoluminescence Images of As-Cut Wafers and Solar Cells. 27th European Photovoltaic Solar Energy Conference. Frankfurt, Germany2012. 
[102] Wang B, Leadbetter A, Seipel B. Measuring Stress in Si Ingots Using Linear Birefringence. Energy Procedia. 2013;38:959-67.

[103] Lich J, Turek M. Correlation Between Different Carrier-Lifetime Measurement Methods For SiBlocks. Energy Procedia. 2011;8:58-63.

[104] Hu Y, Schøn H, Arnberg L. Characterization of defect patterns in Cz silicon slabs by carrier densityimaging. Journal of Crystal Growth. 2013;368:6-10.

[105] Herlufsen S, Bothe K, Schmidt J, Brendel R, Siegmund S. Dynamic photoluminescence lifetime imaging of multicrystalline silicon bricks. Solar Energy Materials and Solar Cells. 2012;106:42-6.

[106] Trupke T, Mitchell B, Weber JW, McMillan W, Bardos RA, Kroeze R. Photoluminescence Imaging for Photovoltaic Applications. Energy Procedia. 2012;15:135-46.

[107] Wang K, Green MA, Kampwerth H. Transient photoconductance and photoluminescence from thick silicon wafers and bricks: Analytical solutions. Solar Energy Materials and Solar Cells. 2013;111:189-92.

[108] Bidiville A, Wasmer K, Michler J, Nasch PM, Van der Meer M, Ballif C. Mechanisms of wafer sawing and impact on wafer properties. Progress in Photovoltaics: Research and Applications. 2010;18:563-72.

[109] A. Grün AL, R. Porytskyy, O. Anspach Investigation of Wafer Surfaces with Space-Resolved Breaking Strength Tests and Corresponding Analysis of the Crack Depth. 26th European Photovoltaic Solar Energy Conference. Hamburg, Germany2011.

[110] A. Bidiville KW, J. Michler, C. Ballif, M. van der Meer, P.M. Nasch Influence of Abrasive Concentration on the Quality of Wire-Sawn Silicon Wafers. 23rd European Photovoltaic Solar Energy Conference. Valencia, Spain2008.

[111] D. Heppner RS, A. Daridon, P.M. Nasch, M. Yin New Cost Saving c-Si PV Wafer Slicing Process by Advanced Wire Technology. 26th European Photovoltaic Solar Energy Conference. Hamburg, Germany2011.

[112] Wu H, Melkote SN. Study of Ductile-to-Brittle Transition in Single Grit Diamond Scribing of Silicon: Application to Wire Sawing of Silicon Wafers. Journal of Engineering Materials and Technology. 2012;134:041011-.

[113] A. Bidiville KW, R. Kraft, C. Ballif Diamond Wire-Sawn Silicon Wafers - from the Lab to the Cell Production. 24th European Photovoltaic Solar Energy Conference. Hamburg, Germany2009.

[114] Yang C, Mess F, Skenes K, Melkote S, Danyluk S. On the residual stress and fracture strength of crystalline silicon wafers. Applied Physics Letters. 2013;102:021909-5.

[115] Chasiotis I, Cho SW, Jonnalagadda K. Fracture Toughness and Subcritical Crack Growth in Polycrystalline Silicon. Journal of Applied Mechanics. 2005;73:714-22.

[116] Wu H, Melkote SN, Danyluk S. Mechanical Strength of Silicon Wafers Cut by Loose Abrasive Slurry and Fixed Abrasive Diamond Wire Sawing. Advanced Engineering Materials. 2012;14:342-8.

[117] A. Bidiville JH, K. Wasmer, S. Habegger, F. Assi. Diamond Wire Wafering: Wafer Morphology in Comparison to Slurry Sawn Wafers. 25th European Photovoltaic Solar Energy Conference and Exhibition / 5th World Conference on Photovoltaic Energy Conversion, . Valencia, Spain2010.

[118] Cai E, Tang B, Fahrner WR, Zhou L. Characterization of the surfaces generated by diamond cutting of crystalline silicon. In: Ossenbrink $\mathrm{H}$, Jager-Waldau A, Helm P, editors. 26th European Photovoltaic Solar Energy Conference. Hamburg, Germany2011.

[119] Bye J-I, Norheim L, Holme B, Nielsen O, Steinsvik S, Jensen SA, et al. Industrialised diamond wire wafer slicing for high efficiency solar cells. In: Ossenbrink $H$, Jager-Waldau A, Helm P, editors. 26th European Photovoltaic Solar Energy Conference and Exhibition. Hamburg, Germany2011.

[120] Meinel B, Koschwitz T, Acker J. Textural development of SiC and diamond wire sawed sc-silicon wafer. Energy Procedia. 2012;27:330-6.

[121] Henley FJ. Kerf-free wafering: Technology overview and challenges for thin PV manufacturing. Photovoltaic Specialists, IEEE Conference2010. p. 1184-92. 
[122] A. Brailove SK, A. Fujisaka, F. Henley First Demonstration of High Volume Manufacturing of KerfFree PolyMax ${ }^{\mathrm{TM}}$ Wafers. 25th European Photovoltaic Solar Energy Conference. Valencia, Spain2010.

[123] Rao RA, Mathew L, Saha S, Smith S, Sarkar D, Garcia R, et al. A novel low cost 25\&\#x03BC;m thin exfoliated monocrystalline Si solar cell technology. Photovoltaic Specialists Conference (PVSC), 2011 37th IEEE2011. p. 001504-7.

[124] Dross F, Baert K, Bearda T, Deckers J, Depauw V, El Daif O, et al. Crystalline thin-foil silicon solar cells: where crystalline quality meets thin-film processing. Progress in Photovoltaics: Research and Applications. 2012;20:770-84.

[125] Dross F, Milhe A, Robbelein J, Gordon I, Bouchard P-O, Beaucarne G, et al. Stress-Induced Lift-Off Method for kerf-loss-free wafering of ultra-thin ( 50um) crystalline Si wafers. Photovoltaic Specialists Conference, 2008 PVSC '08 33rd IEEE2008. p. 1-5.

[126] Bedell SW, Fogel K, Lauro P, Shahrjerdi D, Ott JA, Sadana D. Layer transfer by controlled spalling. Journal of Physics D: Applied Physics. 2013;46:152002.

[127] Martini R, Gonzalez M, Dross F, Masolin A, Vaes J, Frederickx D, et al. Epoxy-Induced Spalling of Silicon. Energy Procedia. 2012;27:567-72.

[128] Bowden S, LeBeau J. Laser wafering. Photovoltaic Specialists Conference (PVSC), 2012 38th IEEE2012. p. 001826-9.

[129] S. Hopman AF, K. Mayer, M. Mesec, G.P. Willeke, D. Kray First Results of Wafering With Laser Chemical Processing. 23rd European Photovoltaic Solar Energy Conference. Valencia, Spain2008.

[130] Daggolu P, Yeckel A, Bleil CE, Derby JJ. Stability limits for the horizontal ribbon growth of silicon crystals. Journal of Crystal Growth. 2013;363:132-40.

[131] Reimann C, Müller G, Friedrich J, Lauer K, Simonis A, Wätzig H, et al. Systematic characterization of multi-crystalline silicon String Ribbon wafer. Journal of Crystal Growth. 2012;361:38-43.

[132] Ciszek TF. Photovoltaic Materials and Crystal Growth Research and Development in the GigaWatt Era. Journal of Crystal Growth.

[133] Narasimha S, Crotty G, Krygowski T, Rohatgi A, Meier DL. Back surface field and emitter passivation effects in the record high efficiency n-type dendritic web silicon solar cell. Photovoltaic Specialists Conference, 1997, Conference Record of the Twenty-Sixth IEEE1997. p. 235-8.

[134] U. Hess SJ, S. Seren, G. Hahn, T. Weber, P.-Y. Pichon, A. Schönecker First Ribbon Growth on Substrate (RGS) Solar Cells with Selective Emitter. 26th European Photovoltaic Solar Energy Conference. Hamburg, Germany2012.

[135] Radhakrishnan HS, Dross F, Debucquoy M, Rosenits P, Van Nieuwenhuysen K, Gordon I, et al. Evaluation of the influence of an embedded porous silicon layer on the bulk lifetime of epitaxial layers and the interface recombination at the epitaxial layer/porous silicon interface. Progress in Photovoltaics: Research and Applications. 2013:n/a-n/a.

[136] Depauw V, Qiu Y, Van Nieuwenhuysen K, Gordon I, Poortmans J. Epitaxy-free monocrystalline silicon thin film: first steps beyond proof-of-concept solar cells. Progress in Photovoltaics: Research and Applications. 2013;19:844-50.

[137] Dross F DV, Kuzma-Filipek I, Van Hoeymissen J, Van Nieuwenhuysen K, Sivaramakrishnan Radhakrishnan H, Gordon I, Poortmans J. Frommicroto. Macro-pores: tuning porous silicon layers for crystalline silicon thin-film solar cells. E-MRS Fall 20132013.

[138] Hernandez D, Trifonov T, Garin M, Alcubilla R. "Silicon millefeuille": From a silicon wafer to multiple thin crystalline films in a single step. Applied Physics Letters. 2013;102:172102-4.

[139] van Mölken JI, Yusufoğlu UA, Safiei A, Windgassen H, Khandelwal R, Pletzer TM, et al. Impact of Micro-Cracks on the Degradation of Solar Cell Performance Based On Two-Diode Model Parameters. Energy Procedia. 2012;27:167-72.

[140] Kajari-Schršder S, Kunze I, Kšntges M. Criticality of Cracks in PV Modules. Energy Procedia. 2012;27:658-63. 
[141] Kajari-Schroder S, Kunze I, Eitner U, Kontges M. Spatial and directional distribution of cracks in silicon PV modules after uniform mechanical loads. Photovoltaic Specialists Conference (PVSC), 2011 37th IEEE2011. p. 000833-7.

[142] M. Köntges IK, S. Kajari-Schröder, X. Breitenmoser and B. Bjørneklett. Quantifying the risk of power loss in PV modules due to micro cracks. 25th European Photovoltaic Solar Energy Conference. Valencia, Spain2010.

[143] Dietrich S, Sander M, Pander M, Ebert M. Interdependency of mechanical failure rate of encapsulated solar cells and module design parameters. 2012. p. 84720P-P-9.

[144] Sander M, Dietrich S, Pander M, Schweizer S, Ebert M, Bagdahn J. Investigations on crack development and crack growth in embedded solar cells. 2011. p. 811209--10.

[145] Kent Kernahan PC, Marc Stewart. Solar Cell Microcracks Are Inevitable, And idealPV FOZHS Makes Them Irrelevant. http://idealpv.com/: idealPV; 2012.

[146] Rupnowski P, Sopori B. Strength of silicon wafers: fracture mechanics approach. International Journal of Fracture. 2009;155:67-74.

[147] Y.K. Park MCW, N.Stoddard, M. Bennett and G. A. Rozgonyi. Correlation between wafer fracture and saw damage introduced during cast silicon cutting. In: Sopori B, editor. 15th Workshop on Crystalline Silicon Solar Cells and Modules: Materials and Processes. Vail, Colorado2005.

[148] Reimann C, Trempa M, Jung T, Friedrich J, Müller G. Modeling of incorporation of O, N, C and formation of related precipitates during directional solidification of silicon under consideration of variable processing parameters. Journal of Crystal Growth. 2010;312:878-85.

[149] T. Buonassisi SR, R. Sweeney, M.D. Pickett, W. Huang, J. Lesniak, M.L. Spencer. Evolution of stresses in wafer bulks and edges during industrial solar cell processing. Proc 22nd European Photovoltaic Solar Energy Conference and Exhibition, . Milan, Italy2007.

[150] Du G, Zhou L, Rossetto P, Wan Y. Hard inclusions and their detrimental effects on the wire sawing process of multicrystalline silicon. Solar Energy Materials and Solar Cells. 2007;91:1743-8.

[151] Du G, Chen N, Rossetto P. On-wafer investigation of SiC and Si3N4 inclusions in multicrystalline Si grown by directional solidification. Solar Energy Materials and Solar Cells. 2008;92:1059-66.

[152] Naumann V, Lausch D, Graff A, Werner M, Swatek S, Bauer J, et al. The role of stacking faults for the formation of shunts during potential-induced degradation of crystalline $\mathrm{Si}$ solar cells. physica status solidi (RRL) - Rapid Research Letters. 2013;7:315-8.

[153] Søndenå R, Hu Y, Juel M, Syre Wiig M, Angelskår H. Characterization of the OSF-band structure in n-type $\mathrm{Cz}$-Si using photoluminescence-imaging and visual inspection. Journal of Crystal Growth. 2013;367:68-72.

[154] J. Haunschild JB, I.E. Reis, S. Rein Quality Control of Czochralski Grown Silicon Wafers in Solar Cell Production Using Photoluminescence Imaging. 26th European Photovoltaic Solar Energy Conference and Exhibition. Hamburg, Germany2011.

[155] Angelskår H, Søndenå R, Wiig MS, Marstein ES. Characterization of Oxidation-Induced Stacking Fault Rings in $\mathrm{Cz}$ Silicon: Photoluminescence Imaging and Visual Inspection After Wright etch. Energy Procedia. 2012;27:160-6.

[156] Dallas W, Polupan O, Ostapenko S. Resonance ultrasonic vibrations for crack detection in photovoltaic silicon wafers. Measurement Science and Technology. 2007;18:852.

[157] Ortner A, Gräff O, Stelzl M, Macherey F, Neubecker R. 'Edge-light': combination of sensitive crack detection and luminescence measurements. Progress in Photovoltaics: Research and Applications. 2013;21:1343-53.

[158] Liu A, Fan Y-C, Macdonald D. Interstitial iron concentrations across multicrystalline silicon wafers via photoluminescence imaging. Progress in Photovoltaics: Research and Applications. 2011;19:649-57.

[159] Olsen E, Flo AS. Spectral and spatially resolved imaging of photoluminescence in multicrystalline silicon wafers. Applied Physics Letters. 2011;99:011903-3. 
[160] M. Wilson AS, F. Buchholz, S. Olibet, R. Kopecek, K. Peter Monitoring of Incoming Silicon PV Wafers with Modified Surface Photovoltage (SPV) Minority Carrier Diffusion Length Method. 26th European Photovoltaic Solar Energy Conference26th European Photovoltaic Solar Energy Conference. Hamburg, Germany2011.

[161] Hameiri Z, Trupke T, Gao N, Sinton RA, Weber JW. Effective bulk doping concentration of diffused and undiffused silicon wafers obtained from combined photoconductance and photoluminescence measurements. Progress in Photovoltaics: Research and Applications. 2013;21:942-9.

[162] Duchamp M, Boothroyd CB, Kovács A, Kadkhodazadeh S, Kasama T, Moreno MS, et al. Mapping boron in silicon solar cells using electron energy-loss spectroscopy. Journal of Physics: Conference Series. 2011;326:012052.

[163] Hahn G, Seren S, Sontag D, Gutjahr A, Laas L, Schonecker A. Over 10\% efficient screen printed RGS solar cells. Photovoltaic Energy Conversion, 2003 Proceedings of 3rd World Conference on2003. p. 1285-8 Vol.2.

[164] Sinton RA, Haunschild J, Demant M, Rein S. Comparing lifetime and photoluminescence imaging pattern recognition methodologies for predicting solar cell results based on as-cut wafer properties. Progress in Photovoltaics: Research and Applications. 2012:n/a-n/a.

[165] Giesecke JA, Michl B, Schindler F, Schubert MC, Warta W. Spatially resolved carrier lifetime calibrated via quasi-steadystate photoluminescence. Energy Procedia. 2011;8:64-70.

[166] Wilson M, Savtchouk A, Lagowski J, Kis-Szabo K, Korsos F, Toth A, et al. QSS- $\mu$ PCD measurement of lifetime in silicon wafers: advantages and new applications. Energy Procedia. 2011;8:128-34.

[167] Belyaev A, Polupan O, Dallas W, Ostapenko S, Hess D, Wohlgemuth J. Crack detection and analyses using resonance ultrasonic vibrations in full-size crystalline silicon wafers. Applied Physics Letters. 2006;88:111907-3.

[168] Pei C, Demachi K, Fukuchi T, Koyama K, Uesaka M. Cracks measurement using fiber-phased array laser ultrasound generation. Journal of Applied Physics. 2013;113:163101-7.

[169] Penot J-D, Massy D, Rieutord F, Mazen F, Reboh S, Madeira F, et al. Development of microcracks in hydrogen-implanted silicon substrates. Journal of Applied Physics. 2013;114:123513-6.

[170] Grisolia J, Assayag GB, Claverie A, Aspar B, Lagahe C, Laanab L. A transmission electron microscopy quantitative study of the growth kinetics of $\mathrm{H}$ platelets in Si. Applied Physics Letters. 2000;76:852-4.

[171] Youssef K, Shi M, Radue C, Good E, Rozgonyi G. Effect of oxygen and associated residual stresses on the mechanical properties of high growth rate Czochralski silicon. Journal of Applied Physics. 2013;113:133502-6.

[172] Fukuzawa M, Yamada M, Rafiqul Islam M, Chen J, Sekiguchi T. Quantitative Photoelastic Characterization of Residual Strains in Grains of Multicrystalline Silicon. Journal of Electronic Materials. 2010;39:700-3.

[173] Hai D, Powell RE, Hanna CR, Ume IC. Warpage measurement comparison using shadow Moire and projection Moire methods. Components and Packaging Technologies, IEEE Transactions on. 2002;25:714-21.

[174] Ganesh RB, Ryningen B, Syvertsen M, Øvrelid E, Saha I, Tathgar H, et al. Growth and characterization of multicrystalline silicon ingots by directional solidification for solar cell applications. Energy Procedia. 2011;8:371-6.

[175] Haunschild J, Glatthaar M, Demant M, Nievendick J, Motzko M, Rein S, et al. Quality control of ascut multicrystalline silicon wafers using photoluminescence imaging for solar cell production. Solar Energy Materials and Solar Cells. 2010;94:2007-12.

[176] Peloso MP, Hoex B, Aberle AG. Polarization analysis of luminescence for the characterization of silicon wafer solar cells. Applied Physics Letters. 2011;98:171914-3.

[177] Xiang L, Li D, Jin L, Pivac B, Yang D. The origin of $0.78 \mathrm{eV}$ line of the dislocation related luminescence in silicon. Journal of Applied Physics. 2012;112:063528-4. 
[178] Schmid E, Funke C, Behm T, Pätzold O, Berek H, Stelter M. Investigation of dislocation structures in ribbon- and ingot-grown multicrystalline silicon. Journal of Crystal Growth. 2013;382:41-6.

[179] Sopori B, Rupnowski P, Balzar D, Sheldon P. Dislocation Generation in Si: A Thermo-Mechanical Model Based on Measurable Parameters. Photovoltaic Energy Conversion, Conference Record of the 2006 IEEE 4th World Conference on2006. p. 936-9.

[180] Nicolai J, Burle N, Serafino C, Pichaud B. Characterizing and modeling the evolution of silicon oxide precipitates during thermal cycles. Journal of Crystal Growth. 2013;372:138-44.

[181] Rip J, Wostyn K, Mertens P, De Gendt S, Claes M. Methodology for Measuring Trace Metal Surface Contamination on Pv Silicon Substrates. Energy Procedia. 2012;27:154-9.

[182] Li J, Prakash RR, Jiptner K, Chen J, Miyamura Y, Harada H, et al. Butterfly-shaped distribution of SiNx precipitates in multi-crystalline Si for solar cells. Journal of Crystal Growth. 2013;377:37-42.

[183] K. Bothe RK, R. Brendel, R. Falster, R. Sinton. Determining the Bulk Lifetime of Unpassivated Multicrystalline Silicon Wafers. 25th European Photovoltaic Solar Energy Conference. Valencia, Spain2010.

[184] Tang X, Francis LA, Gong L, Wang F, Raskin J-P, Flandre D, et al. Characterization of high-efficiency multi-crystalline silicon in industrial production. Solar Energy Materials and Solar Cells. 2013;117:225-30. [185] M. Forster EF, J.M. Lebrun, R. Einhaus, J. Kraiem, M. Lemiti New Method for Grain Size Characterization of a Multi-Crystalline Silicon Ingot. 24th European Photovoltaic Solar Energy Conference. Hamburg, Germany2009.

[186] Sio HC, Xiong Z, Trupke T, Macdonald D. Imaging crystal orientations in multicrystalline silicon wafers via photoluminescence. Applied Physics Letters. 2012;101:082102-4.

[187] Bhushan Sopori PS, and P. Rupnowski. Wafer Breakage Mechanism(s) and a Method for Screening "Problem Wafers". 16th Workshop on Crystalline Silicon Solar Cells and Modules: Materials and Processes. Denver, Colorado2006.

[188] R. Bakowskie RL, T. Kaden, K.G. Eller, D. Lausch, Y. Ludwig, K. Petter Comparison of Recombination Active Defects in Multicrystalline Silicon by Means of Photoluminescence Imaging and Reverse Biased Electroluminescence. 26th European Photovoltaic Solar Energy Conference. Hamburg, Germany2011.

[189] Bakowskie R, Kesser G, Richter R, Lausch D, Eidner A, Clemens P, et al. Fast Method to Determine the Structural Defect Density of 156 x 156 mm2 Mc-Si Wafers. Energy Procedia. 2012;27:179-84.

[190] Meißner D, Schoenfelder S, Hurka B, Zeh J, Sunder K, Koepge R, et al. Loss of wire tension in the wire web during the slurry based multi wire sawing process. Solar Energy Materials and Solar Cells.

[191] Johnston S, Guthrey H, Yan F, Zaunbrecher K, Al-Jassim M, Rakotoniaina P, et al. Correlating Multicrystalline Silicon Defect Types Using Photoluminescence, Defect-band Emission, and Lock-in Thermography Imaging Techniques. Photovoltaics, IEEE Journal of. 2014;4:348-54.

[192] Petter K, Strobel MB, Buss D, Mette M, Ludwig Y, Malik S, et al. Long Term Stability of Solar Modules Made from Compensated SoG-Si or UMG-Si Solar Cells. Energy Procedia. 2011;8:365-70.

[193] Xiao C, Yu X, Yang D, Que D. Study on permanent deactivation of the light-induced degradation in p-type compensated crystalline silicon solar cells. Solar Energy Materials and Solar Cells. 2013;117:2933.

[194] Sievilä P, Mäkinen J, Tilli M, Tittonen I. Dopant-induced stress in microfabricated silicon devices. Journal of Applied Physics. 2013;114:-. 